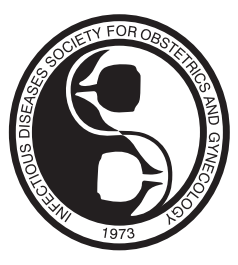

Infectious Diseases Society
for Obstetrics and Gynecology

\title{
Abstracts of the Annual Scientific Meeting and Symposium
}

\author{
August 5-7, 2004 \\ Coronado, California \\ (San Diego) \\ SCIENTIFIC PROGRAM COMMITTEE \\ D. Heather Watts, M.D., Chair \\ Kim Boggess, M.D. \\ Bernard Gonik, M.D. \\ Deborah Money, M.D., FRCSC \\ David Soper, M.D. \\ Harold Wiesenfeld, M.D., CM
}




\title{
SYMPOSIUM
}

NEW DIAGNOSTICS: CHANGING PARADIGMS

\author{
Thursday, August 5, 2004 \\ 8:00 am - 11:45 am \\ 7:00 am \\ Registration Breakfast \\ 8:00 am \\ Welcome - Sharon L. Hillier, Ph.D., IDSOG \\ President Opening Remarks - D. Heather Watts, \\ M.D. Program Chair \\ $8: 15$ am \\ Symposium - New Diagnostics: Changing \\ $8: 15-9: 00$ am \\ Paradigms Moderator: D. Heather Watts, M.D. \\ Bedside Rapid PCR Testing - Ready for Prime Time? \\ Mark Pearlman, M.D. Vice Chair \& Professor, \\ University of Michigan \\ 9:00 - 9:45 am \\ Vaginal Swabs: The Specimen of Choice for \\ Detection of Gonococcal and Chlamydia Infections \\ Julius Schachter, Ph.D. \\ Professor, Laboratory Medicine, Chlamydia \\ Research Lab, University of California, San \\ Francisco \\ 9:45 - 10:00 am BREAK \\ 10:00 - 10:45 am HSV Serology: It's Here to Stay \\ Anna Wald, M.D., MPH \\ Medical Director, Virology Research Clinic \\ Associate Professor, Department of Medicine, \\ Epidemiology and Laboratory Medicine \\ University of Washington
}

Thursday, August 5, 2004

10:45 - 11:30 am

Understanding The Role of Human Papillomavirus

(HPV) in the New Cervical Screening Guidelines

J. Thomas Cox, M.D.

Director, Gynecology Clinic, Health Services

$11: 30-11: 50$ am

University of California, Santa Barbara

$12: 00-1: 30 \mathrm{pm}$

Questions and Answers

Break for Lunch

IDSOG Council Meeting 


\section{SCIENTIFIC PROGRAM}

Thursday, August 5, 2004

Oral Presentations: Session I

Moderator: Harold Wiesenfeld, M.D., CM

$$
1: 30 \mathrm{pm}
$$

$1: 45 \mathrm{pm}$

$2: 00 \mathrm{pm}$

$2: 15 \mathrm{pm}$

$2: 30 \mathrm{pm}$

$2: 45 \mathrm{pm}$

3:00 - 3:45 pm

Thursday, August 5, 2004

Oral Presentations: Session II Moderator: Deborah Money, M.D., FRCSC $3: 45 \mathrm{pm}$

4:00 pm

$4: 15 \mathrm{pm}$

$4: 30 \mathrm{pm}$

$4: 45 \mathrm{pm}$

5:00 pm

Type 2 from Vaginal Swab Specimens

6:00 - 8:00 pm

Friday, August 6, 2004

7:00 am

Oral Presentations: Session III Moderator: D. Heather Watts, M.D. 8:00 am
Macaque Model For Trichomonas Vaginalis Infection

Dorothy Patton, Ph.D.

University of Washington

Characterization of Vaginal Microflora of Healthy, Non-Pregnant Women Using Chaperonin60 Sequence-Based Methods

Deborah Money, M.D., FRCSC

University of British Columbia

Effect of Semen on Vaginal Fluid Cytokines and Secretory Leukocyte Protease Inhibitor

Kathy Agnew

University of Washington Medical Center

The Antimicrobial Peptide as a Vaginal Microbicide

Bernard Moncla, Ph.D.

University of Pittsburgh

A Role For Th1 Directed Immunity in the Prevention of Chlamydia Trachomatis Infection: A Prospective Human Experiment

Craig Cohen, M.D., MPH

University of California, San Francisco

Incidence and Risk Factors for Bacterial Vaginosis (BV) in Women at High Risk for STD's Jane Schwebke, M.D.

University of Alabama at Birmingham

SCIENTIFIC POSTER SESSION (Constellation B)

Long Term Efficacy of Single Dose Metronidazole Therapy in The Treatment of Bacterial Vaginosis

Harold Wiesenfeld, M.D., CM

University of Pittsburgh

A Clinical Trial to Evaluate Efficacy of Maintenance Therapy with $0.75 \%$ Metronidazole Gel (MVG) to Prevent Recurrent Bacterial Vaginosis (BV)

Jack Sobel, M.D.

Wayne State University

Blocking HIV Infection by Mannose-Binding Lactobacilli

Lin Tao, D.D.S., Ph.D.

University of Illinois, Chicago

Methods for Detecting Plasma Cells in Endometrial Biopsies, and Related Microbiologic and Clinical Correlates

Carol Richardson

University of Washington Medical Center

Triage of ASC-US: Evaluating HPV Testing in Adolescents

Cara Stanko, M.D.

Brown University Medical School

Risk Factors for Increased Detection of Herpes Simplex Virus

Thomas Cherpes, M.D.

University of Pittsburgh

IDSOG Welcome Reception (Bay Terrace)

Registration

Breakfast

Rectal Culture is not Necessary When Screening Pregnant Women for Group B

Streptococcal Colonization

Whitney Jamie, M.D.

University of Florida 


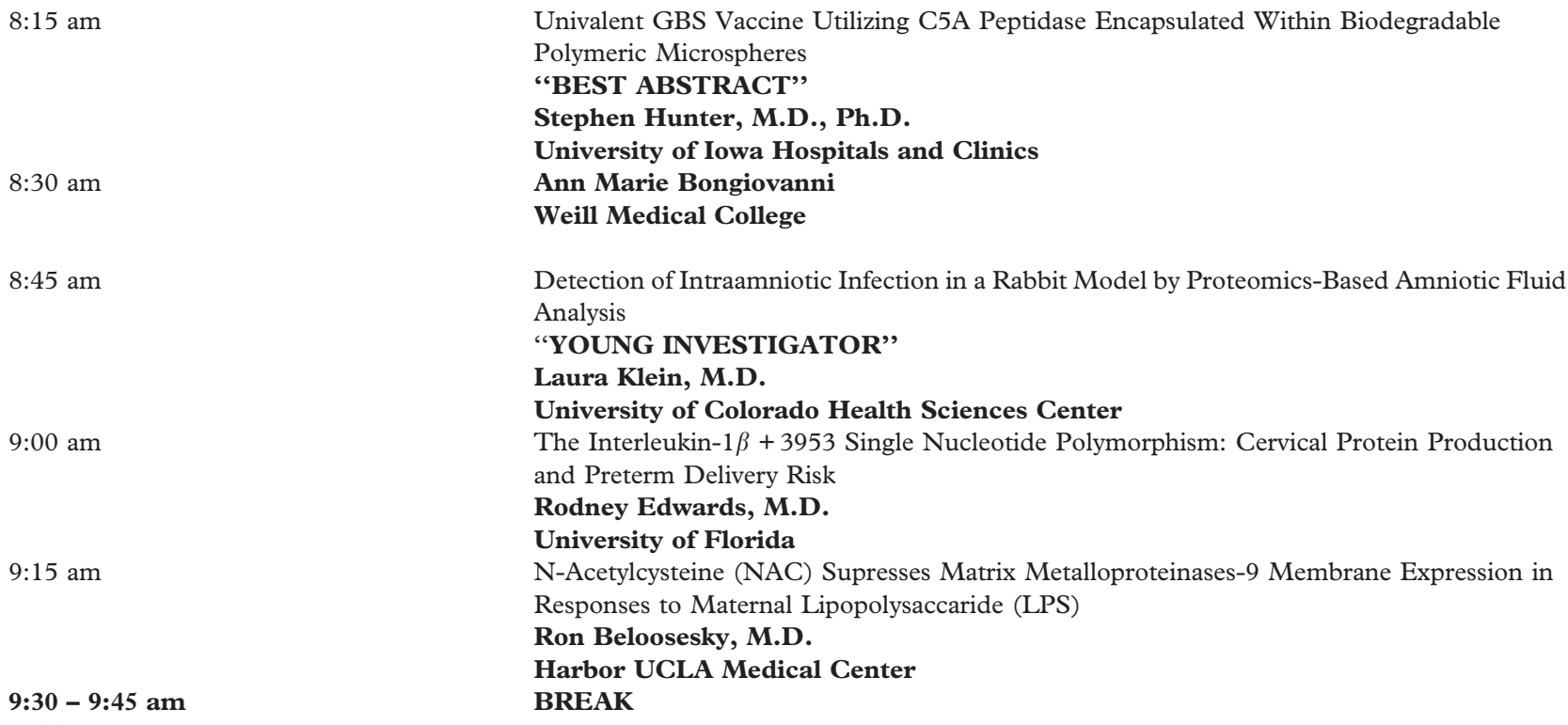

Univalent GBS Vaccine Utilizing C5A Peptidase Encapsulated Within Biodegradable Polymeric Microspheres

"BEST ABSTRACT"

Stephen Hunter, M.D., Ph.D.

University of Iowa Hospitals and Clinics

Ann Marie Bongiovanni

Weill Medical College

Detection of Intraamniotic Infection in a Rabbit Model by Proteomics-Based Amniotic Fluid Analysis

\section{"YOUNG INVESTIGATOR"}

Laura Klein, M.D.

University of Colorado Health Sciences Center

The Interleukin- $\beta+3953$ Single Nucleotide Polymorphism: Cervical Protein Production and Preterm Delivery Risk

Rodney Edwards, M.D.

University of Florida

N-Acetylcysteine (NAC) Supresses Matrix Metalloproteinases-9 Membrane Expression in Responses to Maternal Lipopolysaccaride (LPS)

Ron Beloosesky, M.D.

Harbor UCLA Medical Center

BREAK

Oral Presentations: Session IV Moderator: Kim Boggess, M.D. 9:45 am

10:00 am

10:15 am

10:30 am

$10: 45$ am -12 noon

12:00 noon

6:30 pm

7:00 pm

Saturday, August 7, 2004

7:00 am

Moderator: David Soper, M.D. 8:00 - 9:00 am

Oral Presentations: Session V Moderator: David Soper, M.D. 9:00 am
Impact of Chorioamnionitis on Placental Expression of Prostaglandin Metabolizing Enzymes Emmet Hirsch, M.D.

Northwestern University

Cervical Anti-Inflammatory Cytokine Concentrations are Increased Among Pregnant

Smokers

Hyagriv Simhan, M.D.

University of Pittsburgh

Pro-Inflammatory Cytokines and Other Cell Signaling Analytes Associated With Bacterial Vaginosis Among Pregnant Women

Marijane Krohn, Ph.D.

University of Pittsburgh

Asymptomatic Trichomoniasis During Pregnancy is Associated With Vaginal Neutrophil

Activation

Brenna Anderson, M.D.

University of Pittsburgh

Presidential Guest Lecturer - King K. Holmes, M.D., Ph.D.

Director, Center for AIDS and STD

Chief, Infectious Diseases, University of Washington, Seattle

Randomized Trials of HIVISTI Prevention: What Has Worked, What Hasn't, and Why

IDSOG Business Meeting (Members Only)

Cocktail Reception (Commodore Foyer)

Banquet \& Award Presentations (Commodore A\&B)

\section{Registration}

Breakfast

The Interaction of Stress, Endocrinology, The Immune System, Bacterial Vaginosis and Preterm Birth

Pathik D. Wadhwa, M.D., Ph.D.

Assistant Professor of Psychiatry \& Human Behavior and Obstetrics and

Gynecology

Director, Behavioral Perinatology Research Program

University of California, Irvine College of Medicine

A Pooled Analysis of Risk of Neonatal HSV Infection by Maternal Serostatus at Delivery Elizabeth Brown 


9:15 am
9:30 - 9:45 am
Oral Presentations: Session VI
Moderator: Deborah Money, M.D., FRCSC
9:45 am

10:00 am

Saturday, August 7, 2004

Oral Presentations: Session VI

Moderator: Deborah Money, M.D., FRCSC 10:15 am

Moderator: Sharon L. Hillier, Ph.D. $10: 30 \mathrm{am}$

$11: 30$ am

Adjournment
University of Washington

Cytomegalovirus in Breast Milk: Does it Make Very Premature Babies Ill?

Suzanne Garland, M.D.

Royal Women's Hospital, Australia

BREAK

Measurement of Interleukin 8 in Combination With C-Reactive Protein Reduced

Unnecessary Antibiotic Therapy in Newborn Infants: A Multicenter Randomized Controlled Trial

Suzanne Garland, M.D.

Royal Women's Hospital, Australia

Prevalence \& Risk Factors for HIV in South African Women

Amy Meehan, MPH

University of California, San Francisco

HIV Testing in Pregnancy: An Evaluation of An Opt-Out Strategy in a Women's Health Ambulatory Care Clinic Setting

Mark Yudin, M.D., MSc

University of Toronto

Training Issues in Ob-Gyn Infectious Diseases

Richard Beigi, M.D.

Craig Cohen, M.D., MPH

Sebastian Faro, M.D., Ph.D.

George Wendel, M.D.

Closing Remarks - Sharon L. Hillier, Ph.D.

IDSOG President 


\section{Scientific Posters}

\section{Poster 1}

Transfer of Meropenem in The Ex Vivo Human Placenta Perfusion Model

Michael Hnat, D.O.

University of Texas Southwestern Medical Center

Poster 2

Unilateral Twin Ectopic Pregnancy In A Patient With Multiple Sexually Transmitted Infections

Charles Rolle, M.D.

University of Texas Southwestern Medical School, Dallas

Poster 3

Association of IL-1 Receptor Antagonist Gene Polymorphisms With Increased Rate of Preterm Labor and Premature Rupture of Membranes

Angel Nieves, M.D., Ph.D.

Duke University Medical Center

Poster 4

Trimethoprim-Sulfamethoxazole (TMP-SMX) Prophylaxis For HIV in Pregnancy: A Cost-Effectiveness Analysis

Geeta Swamy, M.D.

Duke University Medical Center

Poster 5

Treatment of Vulvar Vestibulitis: Experience From A Specialty Clinic

Carolyn Gardella, M.D., MPH

University of Washington

Poster 6

HIV Testing Experiences During Pregnancy

Mark Yudin, M.D., MSc

University of Toronto

Poster 7

Medical Records and Women's Self-Report are not Reliable Sources For Determining Whether Antenatal HIV Testing Was Done

Mark Yudin, M.D., MSc

University of Toronto

Poster 8

High Prevalence of Chlamydia and Bacterial Vaginosis In A Low-Risk Population of Pregnant Women Receiving Prenatal Care in El Salvador

Eve Zaritsky, M.D.

University of California, San Francisco

Poster 9

Impact of Concurrent Infections on Genitourinary Symptoms

Jeanna Piper, M.D.

University of Texas Health Science Center, San Antonio 


\section{Scientific Posters}

\section{Poster 10}

Admission Factors Associated With Bacteremia in Gestational Pyelonephritis

Tony Wen, M.D.

University of Texas Health Science Center, San Antonio

\section{Poster 11}

Is Receipt of Intrapartum Antibiotics (IPABX) Associated With An Increased Risk of Postnatal Candidiasis? Mara Dinsmoor, M.D., MPH

Northwestern University

Poster 12

Social Context and The Risk of Sexually Transmitted Infections Among Sex Workers

Deborah Cohan, M.D., MPH

University of California, San Francisco

Poster 13

Lower Genital Tract Infections in Pregnant Adolescents

Andrea Ries Thurman, M.D.

Medical University of South Carolina

Poster 14

Antimicrobial Susceptibility of Facultative and Anaerobic Bacteria Isolated From

The Vagina

Michele Austin

University of Pittsburgh

Poster 15

Long Term Recurrence of Bacterial Vaginosis Following Treatment With 7 Days of Oral Metronidazole, and Evaluation of a Bedside Test For The Diagnosis Of BV

Suzanne Garland, M.D.

Royal Women's Hospital, Australia 


\section{Scientific Poster \#1}

\section{TRANSFER OF MEROPENEM IN THE EX VIVO HUMAN PLACENTA PERFUSION MODEL}

Michael Hnat, DO and Roger E Bawdon, PhD

Objectives: To determine maternal-fetal transplacental passage of meropenem in the ex vivo human perfusion model.

Study Design: Term placentae $(n=6)$ were collected immediately after delivery. A single cotyledon was localized, perfused and stabilized with physiologic Eagles minimal essential medium containing 3\% bovine albumin and heparin as described by Chalier. ${ }^{1}$ Meropenem was added to the maternal medium in concentrations similar to maternal serum peak and trough levels, then perfused through the maternal circulation of the cotyledon. To asses transfer and accumulation, fluid aliquots from both the maternal and fetal compartments were collected over an hour at defined intervals in a open and closed system. Antipyrine ${ }^{14} \mathrm{C}$ was added to the medium in order to calculate the transport fraction and clearance indexes. Meropenem and antipyrine ${ }^{14} \mathrm{C}$ concentrations were determined by High-pressure Liquid Chromatography and liquid scintillation, respectively.

Results: Mean antipyrine transport fraction was $2.33+0.25$. Maternal and fetal mean meropenem peak concentrations were $54.3+3.3 \mathrm{ug} / \mathrm{ml}$ and $2.2+0.18 u \mathrm{~g} / \mathrm{ml}$, respectively. Whereas, maternal and fetal mean trough concentrations were $12.7+1.3 \mathrm{ug} / \mathrm{ml}$ and $0.41+0.10 u \mathrm{~g} / \mathrm{ml}$, respectively. Mean peak clearance index was $0.077+0.007$ and the mean trough was $0.052+0.015$. Mean accumulation for the peak and trough meropenem concentrations were $3.06 \pm 0.28 \mathrm{ug} / \mathrm{ml}$ and $0.74 \pm 0.23 \mathrm{ug} / \mathrm{ml}$, respectively.

Conclusions: Transplacental passage of meropenem with accumulation was noted in the ex vivo human placental perfusion model.

\section{Reference}

1. Chalier JC. Criteria for evaluating perfusion experiments and presentation results. Contrib Gynecol Obstet 1985;13:32-39. 


\section{Scientific Poster \#2}

\section{UNILATERAL TWIN ECTOPIC PREGNANCY IN A PATIENT WITH MULTIPLE SEXUALLY TRANSMITTED INFECTIONS}

Charles J. Rolle, MD, Clifford Y. Wai, MD, Roger Bawdon, PhD, Rigoberto Santos-Ramos, MD, \& Barbara Hoffman, MD

Background: The incidence of unilateral twin ectopic pregnancy is felt to be a rare condition. Several factors increase the risk of ectopic pregnancy, the most important of which is pelvic inflammatory disease, followed by operative trauma, congenital anomalies, tumors and adhesions resulting in anatomically distorted fallopian tubes. We present a case of a woman with four confirmed sexually transmitted infections (STI's) including: Chlamydia trachomatis, Neisseria gonorrhoeae, Herpes simplex virus 2, and Treponema pallidum. The case presented illustrates the impact of sexually transmitted infections (STI's) on the risk of ectopic pregnancy.

Case: A 24 year old primagravida, presented with an unknown last menstrual period, lower abdominal pain, watery vaginal discharge, and vaginal spotting. During this hospitalization, pregnancy testing demonstrated a positive result and transvaginal ultrasonographic examination suggested a non-viable unilateral twin ectopic pregnancy. At exploratory laparotomy, a $10 \mathrm{~cm}$ mass involving the right fallopian tube and ovary was excised. Pathological evaluation of the specimen identified a monochorionic, diamnionic twin ectopic pregnancy within the fallopian tube.

Conclusions: Patients with multiple (STI's) are known to be at risk for the development of chronic pelvic infection and post inflammatory scarring. The resulting distortion of the normal tubal anatomy leads to an increased risk of ectopic pregnancy. 


\section{Scientific Poster \#3}

\section{ASSOCIATION OF IL-1 RECEPTOR ANTAGONIST GENE POLYMORPHISMS WITH INCREASED RATE OF PRETERM LABOR AND PREMATURE RUPTURE OF MEMBRANES}

Nieves AN, Murtha AP, Swamy G, Sinclair TR, Muir H, Yonish B, Booth P, Heine RP

Duke University Medical Center, Durham, NC

Objective: Genetic polymorphisms may influence susceptibility and/or severity to a number of disorders. Allele 2 of the Interleukin-1 receptor antagonist (IL-1RA) gene has been associated with more severe and prolonged pro-inflammatory responses. Our objective was to determine if the allele 2 is associated with preterm delivery.

Study Design: After IRB approval, a case-control study of women admitted to our labor and delivery unit was performed. All patients admitted to labor and delivery for idiopathic preterm labor or preterm premature rupture of membranes were eligible for enrollment. Cases $(n=96)$ were defined as women who were delivered before 37 weeks' gestation after idiopathic preterm labor or preterm premature rupture of membranes. Control subjects $(n=53)$ were selected from an ongoing trial and included women who delivered after 37 weeks gestation without preterm labor or preterm premature rupture of membranes. Genomic DNA from maternal blood was extracted and genotyping was determined by polymerase chain reaction for a length polymorphism in intron 2 of the IL-1RA gene. Data were analyzed using Fisher's Exact Test.

Results: The overall prevalence of at least one copy of IL-1RA polymorphism (intron 2) was 36\% (55/149). Of the 96 cases, $48 \%(47 / 96)$ had at least one copy of allele 2 present compared to $4 \%(8 / 53)$ in the control group $(\mathrm{p}<0.0001)$.

Conclusion: Maternal carriage of at least one copy of the interleukin-1 receptor antagonist allele 2 appears to be associated with increased risk of preterm delivery. 


\section{Scientific Poster \#4}

\section{TRIMETHOPRIM-SULFAMETHOXAZOLE (TMP-SMX) PROPHYLAXIS FOR HIV IN PREGNANCY: A COST-EFFECTIVENESS ANALYSIS}

GK Swamy, MD \& ER Myers, MD/MPH

Duke University Medical Center, Durham, NC

Objective: The World Health Organization recommends daily TMP-SMX for prevention of opportunistic infections in HIV-infected adults. Due to theoretical risks of congenital anomalies from folate antagonism, WHO recommends TMP-SMX only after the first trimester. Given the very low incidence of folate-related anomalies vs. the high morbidity of HIV-related diseases for mother and fetus, we evaluated the health and economic consequences of TMP-SMX use in HIV-infected pregnant women.

Study Design: A decision-analysis model of HIV-infected women living in Africa was constructed to compare three scenarios: 1) current WHO recommendation of discontinuing TMP-SMX with conception and restarting after the first trimester; 2) continuing TMP-SMX throughout pregnancy; and 3) discontinuing TMP-SMX throughout pregnancy. Cost and probability data were derived from published literature and local estimates. Model construction and analyses were performed using DATA 4.0 (TreeAge Software, Williamstown, MA).

Results: Under baseline assumptions, we calculated the average cost per folate-related anomaly prevented. Discontinuing TMP-SMX use during the $1^{\text {st }}$ trimester only had the lowest cost at $\$ 1,268,500$. Since the other strategies are dominated, incremental cost per anomaly prevented cannot be calculated. Assuming folic acid supplementation, discontinuing TMP-SMX during the $1^{\text {st }}$ trimester still had the lowest cost at $\$ 1,274,000$. While continuing TMP-SMX throughout gestation remains dominated, discontinuing use throughout pregnancy costs $\$ 15,163$ per anomaly prevented. The probability of resuming TMP-SMX use in the $2^{\text {nd }}$ trimester significantly impacts the model; if $30 \%$ of women fail to resume therapy, continuing TMP-SMX throughout gestation becomes the least costly strategy.

Conclusion: Discontinuation of TMP-SMX in the first trimester of pregnancy will reduce the incidence of folate-associated congenital anomalies, but simultaneously increase the risk of maternal morbidity. Complete discontinuation may increase the risk of perinatal HIV transmission. Estimates of feasibility of appropriately implementing TMP-SMX use and folic acid supplementation are needed. 


\section{Scientific Poster \#5}

\section{TREATMENT OF VULVAR VESTIBULITIS: EXPERIENCE FROM A SPECIALTY CLINIC}

Carolyn Gardella, MD, MPH, Sylvia Berry, ARNP, \& David Eschenbach, MD

University of Washington

Objective: To review the outcomes of women with vulvar vestibulitis syndrome (VVS) treated with intralesional steroids.

Study Design: The charts of all women with confirmed VVS by Friedrich's criteria seen by a single clinician at the Vulvovaginal Specialty Clinic between February and June 2001 were reviewed for demographic, historical and lab data, therapy and outcomes defined as improvement in pain with intercourse, tenderness to cotton-swab palpation, vestibular erythema, and levator muscle hypertonus.

Results: Of 103 women seen during this time period, 50 were seen for suspected VVS; 37 meet criteria for VVS without any vulvovaginal diagnosis. Three women moved before treatment completion, 2 did not follow-up or wish to have prescribed treatment, and for 11 , charts were missing. This left 21 charts for review. The study population was predominately white with a mean age of 31.5 years. Symptoms were present for 27 months on average (range 6-84). At initial evaluation, 20 of 21 patients had negative $\mathrm{KOH}$ prep but $11(50 \%)$ of 21 had a positive vaginal yeast culture (10 Candida albican) despite the absence of clinical findings of yeast vaginitis. Women were followed for 19 months on average (range 9-36 months). All subjects initially were treated with topical steroids $(0.25 \%$ desoximetasone ointment) applied to the vestibule twice daily for a mean of 11 weeks (range 1-24). Due to lack of resolution of symptoms, all women then received weekly intralesional injections of $4 \mathrm{mg}$ of betamethasone and $4 \mathrm{cc}$ of $0.5 \%$ bupivicaine with epinephrine for a mean of 9 injections (range 3-27). In addition, $12(57 \%)$ of 21 women received yeast suppressive therapy. Physical therapy for levator muscle hypertonus was needed for $14 / 21(67 \%)$ women. All women reported $\geqslant 80 \%$ improvement in VVS symptoms after treatment and $68 \%$ reported complete resolution of symptoms. For those prescribed yeast suppressive therapy, $10(83 \%)$ of 12 reported complete resolution of symptoms, compared with 4 (44\%) of 9 women who were not prescribed yeast suppressive therapy.

Conclusions: Intralesional steroids combined with anti-fungals and physical therapy may be effective in the treatment of VVS. A randomized controlled trial to confirm these findings and determine the relative contributions of each treatment modality is warranted. The high prevalence of yeast by culture despite lack of a clinical diagnosis of vulvocandidiasis among women with VVS supports the biologic plausibility for empiric yeast suppressive therapy in these women. 


\section{Scientific Poster \#6}

\section{HIV TESTING EXPERIENCES DURING PREGNANCY}

A Barbara, MS, D Guenter, MD, MPH, R Zlotnik-Shaul, PhD, MH Yudin, MD, MSc, \& S King, MD University of Toronto and MacMaster University, Hospital for Sick Children and St. Michael's Hospital, Departments of Family Practice, Pediatrics, and Obstetrics and Gynecology, Toronto and Hamilton, Ontario, Canada

Objective: To explore women's HIV testing experiences during pregnancy and to gather information on possible reasons for having an unknown HIV status.

Study Design: Post-partum women were recruited for participation at three Toronto teaching hospitals from November 2002 to February 2004. Women were approached 3 to 155 hours post-partum in hospital and interviewed about their HIV testing experiences during their recent pregnancy.

Results: A total of 299 women were interviewed (67\% of those approached). $99.8 \%$ of participants reported having had any prenatal care. While $73 \%$ of the women interviewed claimed that a health care provider had talked to them about having an HIV test during pregnancy, fewer women $(60 \%)$ indicated that a health care provider discussed the topic of HIV in general. Of the 219 women with whom HIV testing was discussed, $80 \%$ felt that it was a routine test, the same as all other antenatal blood tests; $71 \%$ felt they had the option to refuse the HIV test if they wished; $14 \%$ wished they had more information before making a decision about the test; $87 \%$ stated that they were satisfied with how the HIV test was explained to them; and $90 \%$ agreed to the test. Of the 18 women who declined testing, the most common reasons given were: tested before this pregnancy $(50 \%)$ and not at risk for HIV $(40 \%)$. Of those women $(n=12)$ who claimed to be unsatisfied with the HIV test explanation, all believed that they had been tested for HIV during their pregnancy.

Conclusions: These data suggest that Ontario's goal of offering all women HIV testing by informed consent has not been reached, with shortfalls in offering testing, and in giving women the option to decline. In spite of this shortfall in "best practice", most women feel that they are receiving adequate information and are satisfied with their testing experience. 


\section{Scientific Poster \#7}

\section{MEDICAL RECORDS AND WOMEN'S SELF-REPORT ARE NOT RELIABLE SOURCES FOR DETERMINING WHETHER ANTENATAL HIV TESTING WAS DONE}

D Guenter, MD, MPH, R Zlotnik-Shaul, PhD, A Barbara, MS, MH Yudin, MD, MSc, R Remis, MD, C Swantee, \& S King, MD

University of Toronto and MacMaster University, Hospital for Sick Children and St. Michael's Hospital, Departments of Family Practice, Pediatrics, Obstetrics and Gynecology, and Public Health, Ontario Ministry of Health and Longterm Care, Toronto and Hamilton, Ontario, Canada

Objective: In preparation for a study that will offer rapid HIV testing during labor, we set out to determine whether the medical record and the self-report of a post-partum patient provide reliable information about whether or not antenatal testing has been done.

Study Design: Women were recruited for participation following labor and delivery on the postpartum wards of two Toronto teaching hospitals from November 2002 to August 2003. Following informed consent, the presence or absence of antenatal HIV testing was assessed by three approaches: (1) interviews with women 4 to 152 hours post-partum; (2) review of the labor and delivery charts; and (3) Provincial Laboratory HIV Testing Database and Prenatal Testing Database.

Results: 286 women were approached for participation, and 199 consented (70\%). All women had at least two antenatal care visits, and $94 \%$ had antenatal records on their labor and delivery charts; $55 \%$ had documentation of HIV status on their charts; $44 \%$ had documentation that HIV testing was performed; and $46 \%$ had documentation of HIV test counseling. In interviews, $73 \%$ recalled their provider talking to them about HIV testing and $74 \%$ reported having an HIV test during this pregnancy. Laboratory test results in the two laboratory databases could be found for $66 \%$ of these women within one year of their delivery date. Medical records tended to underestimate the number of women who had been tested. Self-report tended to overestimate the number of women who had been tested.

Conclusions: In this group of women, health records and patient reports are both unreliable for determining who has had HIV testing and who has not had testing during pregnancy. This raises a challenge for offering rapid testing during labor and delivery. 


\title{
Scientific Poster \#8
}

\section{HIGH PREVALENCE OF CHLAMYDIA AND BACTERIAL VAGINOSIS IN A LOW-RISK POPULATION OF PREGNANT WOMEN RECEIVING PRENATAL CARE IN EL SALVADOR}

\author{
Zaritsky E, MD, \& Foster-Rosales A, MD, MPH
}

Objectives: Determine the prevalence and risk factors of sexually transmitted infections (STI) in pregnant women in El Salvador to help illustrate the need for an intervention and screening strategy.

Study Design: Consecutive women attending a prenatal hospital clinic in San Miguel, El Salvador answered a survey on STI knowledge, family planning and symptoms, and underwent screening for Chlamydia trachomatis and Neisseria gonorrhoeae by ligase chain reaction (LCR), Trichomonas vaginalis by wet mount and culture, and bacterial vaginosis by Amsel's criteria.

Results: A total of 444 patients were studied. The mean age was 22 years ( \pm 5.3 ) with an average gestation of 18 weeks $( \pm 7.5)$. Fifty-two percent were nulliparous. C. trachomatis, $N$.gonorrhoeae, $T$. vaginalis, and bacterial vaginosis were detected in $8.3 \%, 0.9 \%, 3.6 \%$ and $37.6 \%$, respectively. For women under 25 years the prevalence of $C$. trachomatis was $9.8 \%$, versus $4.1 \%$ for 25 years and older $(\mathrm{p}<.05)$. Similarly single women had a higher prevalence of $C$. trachomatis than married $(20.7 \%$ vs. $7.5 \%, \mathrm{p}<.05)$. Women less than 25 years had a higher prevalence of BV than those $\geqslant 25$ years of age $(41.3 \%$ vs. $28.0 \%, p<.01)$. Symptoms failed to predict of $C$. trachomatis or bacterial vaginosis.

Conclusion: The high prevalence of $C$. trachomatis and bacterial vaginosis in this population has serious implications for preterm birth, neonatal conjunctivitis, HIV transmission, and future fertility. Therefore, to prevent these serious sequelae, a strategy to screen and/or provide empiric therapy for these genital tract infections may be strongly advised for young, single women presenting for prenatal care in El Salvador. 


\section{Scientific Poster \#9}

\section{IMPACT OF CONCURRENT INFECTIONS ON GENITOURINARY SYMPTOMS}

JM Piper, JE Korte, TS Wen, RN Shain, AEC Holden, JD Champion

Department of Obstetrics and Gynecology, University of Texas Health Science Center at San Antonio

Objective: To determine the impact of concurrent vaginal infections on the genitourinary symptoms of cervicovaginal sexually transmitted diseases.

Study Design: 385 non-pregnant women with gonorrhea (GC), chlamydia (CT) or trichomonas (TV) were extensively questioned about symptoms, and were tested for bacterial vaginosis (BV) and candida (CA) infections. Symptomatology in women infected with GC, CT, or TV alone, and with combination infections $(\mathrm{TV} \pm \mathrm{GC} / \mathrm{CT} / \mathrm{BV} / \mathrm{CA}, \mathrm{GC} \pm \mathrm{CT} / \mathrm{BV} / \mathrm{CA}, \mathrm{CT} \pm \mathrm{BV} / \mathrm{CA})$ was compared to symptoms reported 6 months later when proven free of infection (97 women). Multinomial regression was used to identify symptoms significantly associated with infection.

Results: Rates of symptomatology by group (significant associations in bold).

\begin{tabular}{|c|c|c|c|c|c|c|c|}
\hline & CT only & $\mathrm{CT}+$ & GC only & $\mathrm{GC}+$ & TV only & $\mathrm{TV}+$ & None \\
\hline $\begin{array}{l}\% \text { of women } \\
\text { with symptom }\end{array}$ & $(\mathrm{n}=74)$ & $(n=138)$ & $(n=14)$ & $(n=63)$ & $(n=14)$ & $(\mathrm{n}=82)$ & $(\mathrm{n}=97)$ \\
\hline Itch & 40.5 & 39.1 & 28.6 & 36.5 & 50 & 40.2 & 11.2 \\
\hline Odor & 35.1 & 41.3 & 35.7 & 42.9 & 28.6 & 48.8 & 15.0 \\
\hline Urinary Sx. & 55.4 & 42.8 & 42.9 & 52.4 & 50 & 50 & 35.5 \\
\hline Any Discharge & 68.9 & 61.6 & 71.4 & 68.3 & 57.1 & 68.3 & 27.1 \\
\hline $\begin{array}{l}\text { Severe } \\
\text { discharge }\end{array}$ & 44.6 & 39.1 & 42.9 & 46.0 & 50 & 52.4 & 10.3 \\
\hline $\begin{array}{l}\text { Abdominal } \\
\text { Pain }\end{array}$ & 44.6 & 43.5 & 50 & 52.4 & 42.9 & 30.5 & 25.2 \\
\hline Dyspareunia & 23.0 & 10.9 & 28.6 & 17.5 & 7.1 & 13.4 & 7.5 \\
\hline
\end{tabular}

Conclusions: All groups of infected women had more symptomatology than uninfected women. Although different patterns were noted, there was no clear increase in symptomatology with concurrent (as opposed to individual) infections. 


\section{Scientific Poster \#10}

\section{ADMISSION FACTORS ASSOCIATED WITH BACTEREMIA IN GESTATIONAL PYELONEPHRITIS}

T. Wen, MD, J. Piper, MD, Shari Fox, MD

Department of Ob/Gyn, The University of Texas Health Science Center at San Antonio, San Antonio, Texas.

Objective: To identify factors at the time of admission subsequently associated with bacteremia in pregnant women with gestational pyelonephritis (GP).

Study Design: Women with pyelonephritis during pregnancy or within 4 weeks after delivery were analyzed. Clinical presentation, UTI symptoms, history of UTI, laboratory findings, urine organisms and antibiotic resistance patterns were evaluated in regard to risk for bacteremia (all cases had blood cultures performed). Descriptive statistics and fisher exact or chi-square tests and multinomial logistic regression were used.

Results: To date, 211 GP cases have been analyzed. Urine cultures identified E. coli (86.3\%), K. pneumoniae (6.2\%), P. mirabilis (2.8\%) and other organisms (4.7\%). 62.7\% of urine organisms were resistant to at least 1 antibiotic and $44.2 \%$ had multiple resistances. Bacteremia was identified in $26.5 \%$ of the cases $(66 \%$ of organisms had antibiotic resistance). By univariant analysis, bacteremia was significantly associated with: dysuria, urine leukocytes (tr/ $1+$ vs. $2+/ 3+$ ), urine bacteria (on urinalysis), low hematocrit (Hct), serum creatinine $>0.8$, and antibiotic resistance. Bacteremia was also found to be independently associated with hematocrit (inverse relationship), urine bacteria (too-numerous-to-count or full-field on urinalysis), dysuria and presence of antibiotic resistance by multinomial logistic regression.

Conclusions: Women with gestational pyelonephritis who present with anemia, elevated creatinine, dysuria, bacteriuria and resistant organisms are more likely to have bacteremia. 


\section{Scientific Poster \#11}

\section{IS RECEIPT OF INTRAPARTUM ANTIBIOTICS (IPABX) ASSOCIATED WITH AN INCREASED RISK OF POSTNATAL CANDIDIASIS?}

Mara J. Dinsmoor, MD, MPH, Rebekah Viloria, MD, \& Sonyia Elder, RNC, IBCLC, LCCE

Department of Ob/Gyn; MCV/VCU Hosp Sys, Richmond, VA and Lactation Services, Memorial Regional Medical Center, Mechanicsville, $V A$

IPABX may have adverse effects on neonatal microbial flora. Although the incidence of neonatal oral thrush (THR) is reportedly $4 \%^{1}$, no recent estimates have been reported.

Objectives: To determine: 1) the risk of candidiasis [THR and/or breast infections (BC)] in nursing mother/ baby pairs (NMB), and 2) whether the receipt of IPABX increases this risk.

Study Design: Demographic and obstetric data obtained at delivery, and telephone follow-up obtained at 1 week and one and three months, were recorded in the MRMC Lactation Services database. The diagnoses of THR and BC were based on symptoms and patient reports, as per usual clinical practice. Chi-square analysis and Student t-test were used for analysis. A p-value of $<.05$ was considered significant.

Results: 758 NMB were seen at MRMC between 2/1/01 and 7/30/02. NMB with follow-up who nursed for $\geqslant 1$ month were included $(\mathrm{N}=419)$. $166(40 \%)$ received IPABX, most $(78 \%)$ for GBS prophylaxis. Overall, 39 mother/baby pairs $(9.3 \%)$ had either THR or BC (29 with both) within 1 month of delivery.

IPABX exposed infants were significantly younger $(38.5 \pm 1.9$ vs $39.1 \pm 1.3 \mathrm{wks} ; \mathrm{p}=.001)$, but there were no differences in maternal age, gravity or parity, or route of delivery.

\begin{tabular}{lccc}
\hline & IPABX $(\mathrm{N}=166)$ & No IPABX $(\mathrm{N}=253)$ & P-value \\
\hline Total Candidiasis (n, \%) & $21(12.7 \%)$ & $18(7.1 \%)$ & .056 \\
Thrush (n,\%) & $18(10.8 \%)$ & $15(5.9 \%)$ & 0.13 \\
Breast Cand (n, \%) & $18(10.8 \%)$ & $17(6.7 \%)$ & .068 \\
\hline
\end{tabular}

Conclusions: 1) THR and BC are common postnatal complications 2) The higher rates of THR and BC in IPABX exposed NMB merits further study.

\section{Reference}

1. Kozin, et al. Ped Clin NA 1958;5:803. 


\section{Scientific Poster \#12}

\section{SOCIAL CONTEXT AND THE HEALTH OF SEX WORKERS}

Deborah Cohan, MD, MPH, Johanna Breyer, MSW, Charles Cloniger, MS, NP, Cynthia Cobaugh, Antje Herlyn, Alexandra Lutnick, MA, Daniel Wilson, \& Jeffrey Klausner, MD, MPH

Objectives: Given that health, in general, and risk-taking behavior, in particular, is associated with an individual's psychological state and the sociopolitical context in which they live, we undertook a study to evaluate the association between sex workers' psychosocial contexts and health outcomes.

Study Design: Between September 1999 and February 2003, we conducted a cross-sectional study of sex workers accessing care at St. James Infirmary, a peer-based clinic for sex workers in San Francisco. Each participant underwent a structured intake by a peer counselor addressing demographics, sex work history, health, drug use, legal history, and violence. Analyses were conducted using CDC's Epi Info 2002 statistical software. We used a p-value of 0.05 as a threshold for statistical significance and utilized forward stepwise logistic regression techniques to build our multivariate model.

Results: We saw 535 male, female and transgender sex workers. The participants identified as female (57\%), male $(22 \%)$, and transgender (19\%) and represented a wide range of ethnicities. Nearly half of participants reported current illegal drug use. In additional, $44 \%$ gave a history of having a sexually transmitted infection (STI), and HIV prevalence was $9 \%$. Nearly $50 \%$ of participants reported a history of domestic violence, and $40 \%$ reported a history of sex work-related violence. In multivariate analysis, predictors of having a history of an STI included history of arrest $(2.7 ; 95 \%$ CI 1-6-4.4) and domestic violence (1.8, 95\% CI 1.2-2.8).

Conclusions: Any interventions against HIV and STIs must address the social milieu in which sex workers have sex. Interventions that target violence and the criminal justice system may enhance our ability to address the HIV and STI epidemics in this marginalized population. 


\title{
Scientific Poster \#13
}

\section{LOWER GENITAL TRACT INFECTIONS IN PREGNANT ADOLESCENTS}

\author{
Andrea Ries Thurman, MD \& David E. Soper, MD
}

Objectives: To characterize the incidence of lower genital tract infections (LGTIs) in an adolescent obstetrical population.

Study Design: Pregnant adolescents were screened for bacterial vaginosis (BV), yeast vaginitis, trichomoniasis (Trich), N. gonorrheae (GC), and C. trachomatis (Chla) at their intake obstetric visit and at the 35-37 week visit. Upon admission to labor and delivery (L\&D), a Gram stain of the vaginal secretions was obtained. Gestational age and adverse pregnancy outcomes were recorded.

Results: Data are available for 69 patients at the intake obstetric visit and 31 patients at the 35-37 week visit. At the intake obstetric visit, $33.3 \%(\mathrm{n}=23)$ had BV, $13.0 \%(\mathrm{n}=9)$ had yeast vaginitis, $4.3 \%(\mathrm{n}=3)$ had GC, $14.5 \%$ $(\mathrm{n}=10)$ had Chla, and $4.3 \%(\mathrm{n}=3)$ had Trich. At the $35-37$ week visit, no patients had GC, $3.2 \%(\mathrm{n}=1)$ had Trich., 19.4\% $(n=6)$ had Chla, 16.1\% $(n=5)$ had BV, and $12.9 \%(n=4)$ had yeast. For the 35-37 week LGTIs, $100 \%(n=1)$ of Trich, $50 \%(n=3)$ of Chla, $80 \%(n=4)$ of BV, and $75 \%(n=3)$ of yeast infections were new diagnoses. The rest were recurrent infections from the intake visit, despite receiving treatment. Gram stains were obtained from 94 pregnant teens, with the following results:

Table I. Admission Nugent Scores correlated with Gestational Age at Delivery.

\begin{tabular}{lccc}
\hline Gestational Age & Nugent BV $(7-10)$ & Nugent Intermed. $(4-6)$ & Nugent Normal $(0-3)$ \\
\hline Preterm $(20-366 / 7)$ & 6 & 8 & 16 \\
Term (37 0/7 - 42 6/7) & 8 & 11 & 45 \\
\hline
\end{tabular}

Comparing preterm versus term patients' Nugent scores, there was no difference between patients with normal Nugent scores versus those with an intermediate or BV scores (Chi Square $\mathrm{p}=0.11$ ). For 84 patients, data was available which correlated the teen's L\&D admit Nugent score with intrapartum and post partum febrile morbidity. Five patients ( 1 intrapartum fever and 4 post partum endometritis) with peripartum febrile morbidity had normal admission Nugent scores. Finally, data is available for 25 patients, correlating the 35-37 week screen with subsequent admission Nugent data. At 35 weeks, 3 patients who had BV subsequently had normal Nugent scores at L\&D. For the 22 patients without BV at 35 weeks, 11 had normal Nugent, 6 had intermediate Nugent, and 1 had BV on admit to L\&D.

Conclusions: There are few studies which track LGTIs in pregnant adolescents. LGTIs are common in pregnant adolescents. Repeat screening during pregnancy can be recommended due to a high recurrence/ persistence rate. Teens with preterm delivery had similar Nugent scores on admission as teens delivering at term. Screening for BV at 35-37 weeks does not appear to be predictive of BV at admission for labor. This pilot data will be continued in an ongoing study of the effect of treating LGTIs on adverse pregnancy outcomes in teens. 


\section{Scientific Poster \#14}

\section{ANTIMICROBIAL SUSCEPTIBILITY OF FACULTATIVE AND ANAEROBIC BACTERIA ISOLATED FROM THE VAGINA}

M.N. Austin, S.L. Hillier

Magee-Womens Research Institute, University of Pittsburgh, Department of Obstetrics, Gynecology and Reproductive Sciences

Objective: Our objective was to compare the in vitro susceptibility of facultative and anaerobic bacteria associated with bacterial vaginosis (BV) and two species of Lactobacillus to tinidazole (TIN) and metronidazole (MET).

Study Design: Antimicrobial susceptibility testing was performed using the NCCLS approved agar dilution method. The microorganisms evaluated were recovered from the vagina of women with BV or normal vaginal microflora from 2002-2003. The following groups of bacteria were evaluated: Prevotella bivia, black-pigmented Prevotella spp, non-pigmented Prevotella spp, Porphyromonas spp, Bacteroides spp, Gardnerella vaginalis,

\begin{tabular}{|c|c|c|c|c|c|c|c|}
\hline \multirow[t]{2}{*}{ Organism } & \multirow[t]{2}{*}{$\mathrm{N}$} & \multicolumn{2}{|c|}{$\mathrm{MIC}_{50}(\mathrm{ug} / \mathrm{mL})$} & \multicolumn{2}{|c|}{$\mathrm{MIC}_{90}(\mathrm{ug} / \mathrm{mL})$} & \multicolumn{2}{|c|}{$\%$ Resistant } \\
\hline & & TIN & MET & TIN & MET & TIN & MET \\
\hline P. bivia & 59 & 4 & 4 & 8 & 8 & $0 \%$ & $0 \%$ \\
\hline Prevotella spp & 97 & 2 & 2 & 4 & 8 & $0 \%$ & $0 \%$ \\
\hline $\begin{array}{l}\text { Pig-Prevotella } \\
\text { spp }\end{array}$ & 62 & 2 & 2 & 4 & 4 & $2 \%$ & $0 \%$ \\
\hline Porphyromonas & 43 & 1 & .5 & 1 & 2 & $0 \%$ & $0 \%$ \\
\hline Bacteroides spp & 9 & 2 & 2 & 2 & 4 & $0 \%$ & $0 \%$ \\
\hline Anaerobic GPC & 76 & 2 & 1 & 4 & 4 & $4 \%$ & $1 \%$ \\
\hline G. vaginalis & 102 & 32 & 64 & $>256$ & $>256$ & $54 \%$ & $68 \%$ \\
\hline Lactobacillus & 24 & $>256$ & $>256$ & $>256$ & $>256$ & $96 \%$ & $100 \%$ \\
\hline
\end{tabular}

anaerobic gram positive cocci, and Lactobacillus spp.

Results: Susceptibility of Vaginal Microbes to Tinidazole and Metronidazole. A greater proportion of $G$. vaginalis isolates were metronidazole resistant and tinidazole susceptible than were metronidazole susceptible and tinidazole resistant $(15 \%$ and $1 \%$, respectively, $\mathrm{p}=0.001)$.

Conclusion: Although resistance of vaginal microorganisms to clindamycin is increasingly common, resistance of obligate anaerobic bacteria to azoles including tinidazole and metronidazole is rare. Tinidazole may be more active than metronidazole against Gardnerella vaginalis. 


\title{
Scientific Poster \#15
}

\section{LONG TERM RECURRENCE OF BACTERIAL VAGINOSIS FOLLOWING TREATMENT WITH 7 DAYS OF ORAL METRONIDAZOLE, AND EVALUATION OF A BEDSIDE TEST FOR THE DIAGNOSIS OF BV}

\author{
Bradshaw $\mathrm{CS}^{1,2}$, Morton $\mathrm{AN}^{1}$, Garland $\mathrm{SM}^{3}$, Horvath $\mathrm{LB}^{1}$, Kuzevska $\mathrm{I}^{1}$, Moss $\mathrm{L}^{1}$, Morris $\mathrm{M}^{1}$, \\ \& Fairley CK 1,2 \\ ${ }^{1}$ Melbourne Sexual Health Centre, The Alfred Hospital, Victoria, Australia, ${ }^{2}$ School of Population Health, University \\ of Melbourne, Victoria, Australia, and ${ }^{3}$ Department of Microbiology, The Royal Women's Hospital, Victoria, Australia
}

Objective: Bacterial vaginosis (BV) is the commonest cause of abnormal vaginal discharge in women of childbearing age worldwide. The diagnosis of BV is currently made with Amsel's or Nugent's criteria, which rely on laboratory facilities. This creates delays in diagnosis and treatment for many women. Treatment is recommended for symptomatic $\mathrm{BV}$, and cure rates of $70-80 \%$ at 4 weeks after oral metronidazole are reported; however, few studies have evaluated long-term recurrence.

Study Design: We aim to establish the recurrence rate of BV in 130 symptomatic women after 7 days of oral metronidazole over 12 months, and to evaluate -BV Blue, a rapid bedside test for the diagnosis of BV against Nugent's and Amsel's criteria.

Results: To date 240 women with symptoms of vaginal discharge or odour have been enrolled in the study; of these 95 had BV on Amsel's criteria (39.6\%) and 84 had BV on Nugent's criteria (35.6\%).

BV Blue was sensitive and specific compared to standard criteria: $91.6 \%$ sensitive and $90.9 \%$ specific compared to Amsel's criteria and $94 \%$ sensitive and $86.4 \%$ specific compared to Nugent's criteria.

Preliminary data for the recurrence study shows a relapse rate of BV at one month $(\mathrm{n}=72)$ of $18.1 \%(95 \%$ CI $10.4-28.2 \%)$. The cumulative relapse rate by month $3(n=67)$ is $40.3 \%(29.1-52.3 \%)$, and by month $6(n=46)$ is $51.4 \%(35.1-67.5 \%)$.

Conclusion: BV has been shown to increase susceptibility to HIV and sexually transmitted infections, and to be associated with significant obstetric complications. It is important to establish the long-term efficacy of current first line therapy, and to evaluate alternative methods of diagnosis that do not rely on laboratory facilities to improve diagnosis and management of $\mathrm{BV}$ in the community. 


\section{Thursday, August 5, 2004 1:30 PM Oral Presentations: Session I}

\section{MACAQUE MODEL FOR TRICHOMONAS VAGINALIS INFECTION}

Dorothy Patton, PhD, Kathy Agnew, BS \& Sharon Hillier, PhD

University of Washington, Seattle, WA and Magee Womens Research Institute Pittsburgh, PA

Objectives: Trichomonas vaginalis is a highly prevalent STI that has been associated with increased risk of HIV infection. A reliable animal model of $T$. vaginalis infection would enable scientists to characterize trichomoniasis infection in greater detail than clinical case studies allow.

Study Design: We conducted a pilot study ( $\mathrm{n}=7$ Macaca nemestrina $)$ in which four animals were challenged with $1.0 \mathrm{ml}$ T.vaginalis (ATCC 50148) at $6.6 \times 10^{5}$ trichomonads per $\mathrm{ml}$. Three additional animals were inoculated in the same time frame, with T.vaginalis growth media alone (no trichomonads). Each animal underwent vaginal cultures on days 0 (baseline), 2, 7, 9 and 14 post inoculation. Vaginal cultures were immersed into InPouch ${ }^{\mathrm{TM}} \mathrm{TV}$ culture bags immediately after collection. Cultures were incubated for 72 hours, then assessed under 10X magnification for active trichomonad detection, which was confirmed at 40X. In addition cervical swabs were collected for assessment of cytokine profiles, at baseline (pre-infection), postinfection and post-treatment visits. Samples were tested in the Luminex system.

Results: All four test animals and none of three control animals had Trichomonas vaginalis detected from vaginal swabs by day 2 post-inoculation (pi) which persisted through day 14 of the study. Following oral treatment with metronidazole $(35 \mathrm{mg} / \mathrm{kg} /$ day X3 days), infection was resolved in all animals.

Cytokine analyses revealed $T$. vaginalis infected animals developed increased levels of GM-CSF, IL-4 and MIP- $1 \alpha$ in cervical swabs, compared to control animals (median paired difference test). These cytokines indicate macrophage activation, which suggests an immune response to infection.

Conclusions: These data show that a single inoculation with Trichomonas vaginalis results in infection which persists in the vagina of the pig-tailed macaque. The resultant cytokine profile provides evidence of host immune response.

This work supported by NIH P01 AI39061 and WaNPRC RR-00166. 


\section{Thursday, August 5, 2004 \\ 1:45 PM \\ Oral Presentations: Session I}

\section{CHARACTERIZATION OF VAGINAL MICROFLORA OF HEALTHY, NON-PREGNANT WOMEN USING CHAPERONIN-60 SEQUENCE-BASED METHODS}

Janet E. Hill, PhD, Swee Han Goh, PhD, Deborah M. Money, MD, FRCSC, Melissa Doyle, Andra Li, BSc, William L. Crosby, PhD, Matthew G. Links, BSc, Amy Leung, Debbie Chan, and Sean M. Hemmingsen, PhD.

Objective: The purpose of this study was to use a novel method, based on application of chaperonin-60 (cpn60) sequencing to describe the vaginal microflora of 16 healthy individuals.

Study Design: Asymptomatic women consented for vaginal swabs to be collected at the time of a clinical pelvic examination. Total genomic DNA was isolated from the vaginal swabs. Degenerate, universal PCR primers were used to amplify an approximately $555 \mathrm{bp}$ region of the universal cpn 60 gene, found in all eubacteria and eukaryotes, from the total genomic DNA and libraries of cloned PCR products were constructed. Library clones were sequenced and resulting sequences were assigned to taxonomic groups based on similarity to reference sequence data.

Results: Sixteen of the 23 women enrolled had normal flora by Nugent's scoring $(<4)$ and had adequate PCR product for assessment. Vaginal flora libraries were dominated by a variety of sequences with similarity to Lactobacillus spp. Lactobacilius crispatus, L. iners, L. gasseri, L. jensenii and L.buchneri. Other sequences identified included representatives of Gardnerella spp., sequences with similarity to Porphyromonas spp. and Megasphaera spp. and sequences identical to Chlamydophila psittaci. Presence of C. psittaci sequences in the samples was confirmed by species-specific, quantitative PCR.

Conclusion: Culture-independent, $\operatorname{cpn} 60$ sequence-based molecular methods can lead to the identification of greater diversity within defined taxa compared to those identified by standard culture-based methods, as well as the identification of novel organisms not previously associated with vaginal flora. The development of a highly specific and quantitative molecular method of assessing vaginal flora can lead to a much more sophisticated assessment of the disease entities associated with abnormal vaginal flora. 


\section{Thursday, August 5, 2004}

\section{2:15 PM}

\section{Oral Presentations: Session I}

\section{THE ANTIMICROBIAL PEPTIDE LSA-5 AS A VAGINAL MICROBICIDE}

Moncla BJ, Mietzner TM, Hillier SL

University of Pittsburgh School of Medicine, Departments of Obstetrics, Gynecology and Reproductive Sciences and Molecular Genetics and Biochemistry and the Magee-Womens Research Institute, Pittsburgh, PA 15213

Objective: Vaginal fluid is comprised of numerous components including divalent cations and serum derived proteins. Antimicrobial peptides are being developed for use as topical microbicides for prevention of sexually transmitted infections. Human serum inhibits the activity of several antimicrobial peptides. The purpose of this study was to define factors which may interfere with the activity of the antimicrobial peptide LSA-5 in vaginal fluid.

Study Design: Neisseria gonorrhoeae (GC, 14 strains) and Lactobacillus species (23 strains) were evaluated against LSA-5. Killing was defined as a $99.99 \%$ decrease in viable bacteria in 30 min.

Results: LSA-5 had activity against GC in the absence of serum, but cidal activity was not detected when serum or human serum albumin were present. Addition of EDTA restored cidal activity, suggesting that divalent cations may be responsible for the protective effects of serum. To evaluate this, the activity of LSA- 5 was evaluated against GC and Lactobacillus species at $\mathrm{pH} 5$ and 7 with and without added $\mathrm{Ca}++$ or $\mathrm{Mg}++$ (see below).

\begin{tabular}{|c|c|c|c|c|c|}
\hline & \multirow[b]{2}{*}{ \# strains } & \multirow[b]{2}{*}{$\mathrm{pH}$} & \multicolumn{3}{|c|}{$\%$ Isolates killed by $10 \mu \mathrm{M}$ LSA- 5} \\
\hline & & & $\begin{array}{c}\text { Control (no } \mathrm{Ca}++ \\
\text { or } \mathrm{Mg}++)\end{array}$ & $20 \mathrm{mM} \mathrm{Ca}++$ & $20 \mathrm{mM} \mathrm{Mg}++$ \\
\hline \multirow[t]{2}{*}{ N. gonorrhoeae } & 14 & 5 & $86 \%$ & $0 \%$ & $14 \%$ \\
\hline & & 7 & $93 \%$ & $33 \%$ & $33 \%$ \\
\hline \multirow[t]{2}{*}{ L. crispatus $\left(\mathrm{H}_{2} \mathrm{O}_{2}+\right)$} & 8 & 5 & $0 \%$ & $0 \%$ & $0 \%$ \\
\hline & & 7 & $0 \%$ & $0 \%$ & $0 \%$ \\
\hline \multirow[t]{2}{*}{ L. jensenii $\left(\mathrm{H}_{2} \mathrm{O}_{2}+\right)$} & 15 & 5 & $33 \%$ & $0 \%$ & $7 \%$ \\
\hline & & 7 & $100 \%$ & $0 \%$ & $7 \%$ \\
\hline
\end{tabular}

Conclusions: The cidal activity of LSA- 5 against GC was inhibited by the presence of either $\mathrm{Ca}++$ or $\mathrm{Mg}++$. Lactobacillus species varied in their sensitivity to killing by this peptide, and killing differed with $\mathrm{pH} . \mathrm{Mg}++$ and $\mathrm{Ca}++$ present in vaginal fluid may decrease the cidal activity of some peptides under development as topical microbicides. 


\section{Thursday, August 5, 2004}

2:30 PM

\section{Oral Presentations: Session I}

\section{A ROLE FOR Th1 DIRECTED IMMUNITY IN THE PREVENTION OF CHLAMYDIA TRACHOMATIS INFECTION: A PROSPECTIVE HUMAN EXPERIMENT}

Craig R Cohen, $\mathrm{MD}, \mathrm{MPH}^{1}$, Amalia Meier $\mathrm{PhD}^{1}$, Caixa Shen $\mathrm{X}, \mathrm{KM}$ Koochesfahani $\mathrm{X}^{2}, \mathrm{~K}$ Karunakaran ${ }^{2}$, Teresa Kinyari $\mathrm{MBChB}$, Nelly R Mugo MBChB, MMed, $\mathrm{MPH}^{3}$, Rosemary Nguti $\mathrm{PhD}^{3}$, Robert C Brunham $\mathrm{MD}^{2}$

${ }^{1}$ University of Califormia, San Francisco, USA, ${ }^{2}$ University of Washington, Seattle, USA, ${ }^{3}$ University of British Columbia Center for Disease Control, Vancouver, Canada, and ${ }^{4}$ University of Nairobi, Nairobi, Kenya

Objectives: Epidemiological, animal and in-vitro investigations suggest development of acquired immunity against Chlamydia trachomatis infection. This prospective study was designed to assess the correlation between specific C. trachomatis immunologic factors measured at baseline with the risk of subsequent infection in a highly exposed cohort.

Study Design: Sex workers in Nairobi, Kenya aged 18 to 35 years old were followed every two months for incident $C$. trachomatis infection. IFN- $\gamma$, IL-10 and IL-13 were measured in the supernatant of peripheral blood mononuclear lymphocytes (PBMC) stimulated with serovars E,F,K and L2 EB and cloned recombinant serovar D HSP-60 genotype-1.

Results: Among the 299 women enrolled in the cohort 43 cases of $C$. trachomatis infection were detected during 307 women-years of observation ( $14 \%$ annual incidence). Age (Hazard ratio $(\mathrm{HR})=.9,95 \% \mathrm{CI} .9-1.0)$, $\leqslant 2$ years of prostitution ( $\mathrm{HR}=1.6,95 \%$ CI 1.02-2.4), incident $N$. gonorrhoeae infection (HR=3.4, 95\% CI 1.110.4) but not HIV-infection ( $\mathrm{HR}=1.5,95 \% \mathrm{CI} .6-3.8)$ were associated with incident $C$. trachomatis infection. After adjustment for age and other potential confounders, production of IFN- $\gamma$ (Adjusted (A) HR $=.2,95 \%$ CI .03-.96) and IL-10 (AHR $=5.3,95 \%$ CI .8-34.5) by HSP60 type-1 stimulated PBMC collected at the initial visit correlated with protection and increased susceptibility, respectively to incident $C$. trachomatis infection. Similarly, IL-13 production after stimulation of PBMC by chlamydia EB correlated with protection against infection (AHR $=.2,95 \% \mathrm{CI} .07-.8)$.

Conclusions: To date these are the strongest human data to support a direct role for a $C$. trachomatis specific immune response to prevent infection. If substantiated, these findings suggest that candidate vaccines should elicit a Th-1 response to HSP-60 type 1. 


\section{Thursday, August 5, 2004}

\section{2:45 PM}

\section{Oral Presentations: Session I}

\section{INCIDENCE AND RISK FACTORS FOR BACTERIAL VAGINOSIS (BV) IN WOMEN AT HIGH RISK FOR STDs - CONTINUED EVIDENCE OF SEXUAL TRANSMISSION}

Jane Schwebke, MD \& Renee Desmond, $\mathrm{PhD}$

University of Alabama at Birmingham

Objectives: $\mathrm{BV}$ is the most common type of vaginitis worldwide and is associated with important public health complications. The etiology is unknown. The objective of this study was to determine the risk factors associated with incident BV.

Study Design: 113 women attending an STD Clinic who had no evidence of BV were enrolled into this prospective, longitudinal study. 42 male partners were studied. Women were followed monthly for 6 months then every 3 months for up to one year. Questionnaires and screening for BV/STDs were performed at each visit. Women who developed symptomatic BV were treated with metronidazole and continued in the study. Male partners were interviewed and examined proximate to the woman's baseline study visit.

Results: The rate of incident BV was 3.8 episodes/patient years. The median time to development of BV was 83 days. Women who developed BV were more likely to have a greater number of partners in the last 30 days (2.3) compared to women who did not develop BV (1.0) as well as more vaginal sex episodes in the last 30 days but not significantly so. There was a borderline relationship with BV and the current partner having at least one other sex partner in the last 30 days $(p=0.05)$. Incident $B V$ was highly associated with exposure to a new sex partner $(p=0.004)$. Use of condoms with the secondary partner was protective $(p=0.003)$. Other factors associated with BV were anal sex and douching.

Conclusions: The data strongly suggest that BV is an STD. The precise mechanisms involved in transmission remain unknown, specifically the microbiology and the duration of colonization/infection in the male. 


\section{Thursday, August 5, 2004 \\ 3:45 PM \\ Oral Presentations: Session II}

\section{LONG TERM EFFICACY OF SINGLE DOSE METRONIDAZOLE THERAPY IN THE TREATMENT OF BACTERIAL VAGINOSIS}

Harold C. Wiesenfeld, MD, CM, Kathleen Carroll, MD, Marijane A. Krohn, PhD., Richard L. Sweet, MD, Sharon L. Hillier, PhD

University of Pittsburgh School of Medicine, Magee-Womens Research Institute, Pittsburgh, PA

Objective: A single 2 gram dose of metronidazole is commonly used to treat bacterial vaginosis (BV) and is recommended as an alternative agent by the CDC. The advantages of single dose compared to a one week course of metronidazole include compliance and fewer side effects. Despite the common use of single dose metronidazole, little is known about the long-term efficacy of this regimen for BV. The objective of this study is to determine the long-term efficacy of a single 2 gram dose of metronidazole for the treatment of BV.

Methods: Nonpregnant women 15-30 years old diagnosed with BV by Amsel's criteria were enrolled in a longitudinal study of pelvic infections. All women received a single 2 gram dose of metronidazole, along with empiric treatment for cervicitis (single doses of cefixime and azithromycin). Women were asked to return for follow-up at 12 weeks.

Results: The mean time between enrollment and follow-up for the 252 women was 15 weeks. Clinical cure $(0 / 4$ criteria) was achieved by $41 \%$ of women, and $65 \%$ had clinical resolution of BV ( $<3 / 4$ Amsel's criteria). Microbiologic cure (gram stain score $\leqslant 3$ ) was observed in $35 \%$ and $55 \%$ obtained a score $<7$. The therapeutic cure rate (clinical AND microbiologic cure) was $27 \%$. Variables associated with treatment failure included African American race, smoking, inconsistent condom use, trichomoniasis, and colonization with Mycoplasma hominis.

Conclusion: A single 2 gram dose of metronidazole is associated with low clinical, microbiologic, and therapeutic cure rates 3 months following treatment. Comparative trials evaluating the long-term efficacy of treatment regimens are needed to determine the optimal therapy for BV. 


\section{Thursday, August 5, 2004 \\ 4:15 PM \\ Oral Presentations: Session II}

\section{BLOCKING HIV INFECTION BY MANNOSE-BINDING LACTOBACILLI}

L. Tao ${ }^{1}$, S. I. Pavlova ${ }^{1}$, J. J. Anzinger ${ }^{2}$, A. Jacobs ${ }^{1}$, S. J. Carlson ${ }^{1}$, M. S. Caffrey ${ }^{1}$, G. T. Spear ${ }^{2}$

${ }^{1}$ University of Illinois at Chicago, Chicago, IL, and ${ }^{2}$ Rush University Medical School, Chicago, IL.

Objective: HIV mutates rapidly, shifting antigenicity and rendering vaccines ineffective. The HIV envelope, however, always contains glycoproteins rich in mannose. The aim of this study was to isolate commensal bacteria that trap HIV by binding to its mannose.

Study Design: Saliva and vaginal samples were collected from volunteers. Lactobacilli were isolated on Rogosa agar. Mannose-binding lectin + (MBL) strains were identified by co-aggregation with Saccharomyces cerevisiae. The temperature-sensitive transposon plasmid pGh9:ISS1 was used for mutagenesis. Lactobacilli were tested for binding of various H/SIV envelopes and HIV-target cells. The virus capture ELISA (p24) and luciferasetagged HIV- $1_{\mathrm{HxB} 2}$ were used to analyze bacterial binding of $\mathrm{HIV}-1_{\mathrm{BaL}}$ and blocking of HIV infection in vitro.

Results: Among 500 oral and vaginal Lactobacillus strains tested, 19 coaggregated with S. cerevisiae, of which 11 ( 6 oral and 5 vaginal) bound gp 120 . Two oral strains showed highest binding affinity and were studied further. An MBL mutant was isolated by transposon mutagenesis. OLB19a, but not its isogenic mutant Tm4A3, bound gp120 proteins of multiple HIV clades, gp130 and gp140 of SIV, live HIV viruses, and mulitple HIV-target cells ( $\mathrm{T}, \mathrm{B}$ and $\mathrm{DC}-\mathrm{SIGN}^{+}$cells) with high affinity and in a mannose-dependent manner. Although did not coaggregate with HIV-target cells, OLB-43b bound HIV and displayed significant killing by secreted MBL (size between 3 and $10 \mathrm{kDa}$ ). Its antiviral effect was enhanced by catalase (eliminating $\mathrm{H}_{2} \mathrm{O}_{2}$ ) and reduced by yeast absorption (removing MBL), but not affected by lactic acid or proteinase inhibitor.

Conclusions: Selected MBL + lactobacilli bound HIV, blocked in vitro HIV infection, and coaggregated with HIV-target cells (for cell-associated HIV). Therefore, oral MBL + Lactobacillus strains may potentially protect infants against milk-borne HIV infection, and vaginal MBL + Lactobacillus strains may potentially protect women against sexual HIV transmission. 


\title{
Thursday, August 5, 2004 4:45 PM \\ Oral Presentations: Session II
}

\section{TRIAGE OF ASC-US: EVALUATING THE NEED FOR HPV TESTING IN ADOLESCENTS}

\author{
C Stanko, MD, S Weitzen, PhD, CJ Sung, MD, \& LA Boardman, MD, ScM.
}

Objectives: To determine age-stratified prevalences of oncogenic HPV infection and to evaluate traditional risk factors for HPV acquisition among a cohort of women with ASC-US smears.

Study Design: This was a retrospective chart review of all women with ASC-US smears who underwent oncogenic HPV testing between July 2002 (when reflex testing with Hybrid Capture II was initiated at our site) and July 2003. To be eligible for inclusion, HPV DNA results had to be available. Data extracted from charts included demographic information as well as certain patient characteristics historically associated with HPV acquisition (e.g., number of sexual partners, age at first coitus).

Results: Of the 253 eligible women, 177 (70\%) tested positive for oncogenic HPV subtypes at the time of an ASC-US smear. As compared to women who tested negative, this population was significantly younger (25.3 years versus 28.4 years, $\mathrm{p}=.01)$ and less likely to be married $(13 \%$ versus $26 \%, \mathrm{p}=.03)$. No significant differences between the two groups emerged with respect to smoking history, mean age at first intercourse, mean number of lifetime sexual partners, history of sexually transmitted infections or prior history of abnormal cervical cytology or treatment for neoplasia. A trend was seen in a protective effect of oral contraceptives among oncogenic HPV-positive women ( $13 \%$ versus $21 \%, \mathrm{p}=.10)$. When stratified by age, $86 \%$ of the women under the age of 20 were positive for high-risk subtypes, compared to $53 \%$ of women over the age of $25(p<.01)$. The protective effect of oral contraceptives was most pronounced among adolescent women and did not persist in women over the age of 25.

Conclusions: Given that the rate of oncogenic HPV positivity exceeded $85 \%$ in our population of adolescent women with ASC-US, the usefulness of HPV testing in this age group requires further validation. 


\section{Thursday, August 5, 2004 \\ 5:00 PM \\ Oral Presentations: Session II}

\section{HORMONAL CONTRACEPTION, BACTERIAL VAGINOSIS (BV), AND VAGINAL GROUP B STREPTOCOCCUS (GBS) ARE RISK FACTORS FOR GENITAL TRACT SHEDDING OF HERPES SIMPLEX VIRUS TYPE 2}

Cherpes TL, Melan MA, Kant JA, Cosentino LA, Meyn LA, \& Hillier SL. University of Pittsburgh, Pittsburgh, PA, USA

Background: Herpes simplex virus type 2 (HSV-2), the most common cause of genital ulcerative disease, is characterized by high rates of asymptomatic genital tract shedding and the attendant risk of transmission to sexual partners and neonates. BV has previously been identified as a risk factor for HSV-2 acquisition.

Objective: To identify potentially modifiable risk factors for HSV-2 shedding in women of reproductive age.

Methods: $330 \mathrm{HSV}-2$ seropositive women were evaluated at four month intervals for a year. A vaginal swab specimen from each visit was evaluated for the presence of HSV-2 DNA by real-time PCR amplification, while a second vaginal swab specimen was used for the culture detection of GBS and yeast. Additionally, a vaginal smear was obtained at each visit for the Gram stain diagnosis of BV. Information on sexual activity, contraceptive usage and demographics was collected at each visit using a structured questionnaire.

Results: HSV-2 DNA was detected in 88 (9\%) of the 956 vaginal swab specimens. As previously reported, recent acquisition of HSV-2 infection in the prior four months was associated with an increased risk of shedding, even after accounting for other factors (adjusted odds ratio [aOR], 3.0; 95\% confidence interval [CI], 1.3-6.8). However, a Gram stain diagnosis of $\mathrm{BV}$ (aOR, 2.3; 95\% CI, 1.3-4.0), high-density vaginal GBS colonization (aOR, 2.2; 95\% CI, 1.3-3.8), and use of hormonal contraceptives (aOR, 1.8; 95\% CI, 1.1-2.8) were also identified as independent predictors of genital tract shedding of HSV-2). The trend toward increased shedding of HSV-2 was similar among both oral contraceptive users and women on DepoProvera ${ }^{\mathrm{TM}}$.

Conclusions: Our study identifies BV, high-density vaginal GBS colonization, and hormonal contraceptive use as risk factors for genital tract shedding of HSV-2 in women. These three variables represent potentially modifiable risk factors for HSV-2 genital tract shedding in women. 
Friday, August 6, 2004

8:00 AM

\section{Oral Presentations: Session III}

\section{RECTAL CULTURE IS NOT NECESSARY WHEN SCREENING PREGNANT WOMEN FOR GROUP B STREPTOCOCCAL COLONIZATION}

Jamie WE, MD, Edwards RK, MD, MS, \& Duff P, MD

Objective: To determine whether the rate of recovery of group B streptococcus (GBS) from combined vaginal and perianal cultures is equivalent to combined vaginal and rectal cultures.

Study Design: We performed a prospective cohort study of vagino-perianal versus vagino-rectal culture for GBS. Two hundred pregnant women in the third trimester were enrolled. Three specimens were collected from each patient in the following order: lower third of the vagina, perianal skin, and rectum. Each specimen was cultured serially in selective broth media then on sheep's blood agar. Suspicious colonies were confirmed by latex agglutination. Culture positivity rates from the combined sites of vagina and perianal area were compared with vagina and rectum.

Results: Of the 200 subjects, $71(36 \%)$ had a positive culture from at least one site. Vaginal culture was positive in 55 patients (28\%), compared to 48 patients $(24 \%)$ with positive perianal cultures and 50 patients (25\%) with positive rectal cultures. Combined vaginal and perianal cultures were positive in 68 patients $(34 \%)$ compared to combined vaginal and rectal cultures positive in 67 patients $(34 \%)(\mathrm{p}=1.0)$.

Conclusion: The GBS detection rate from vagino-perianal specimens is not significantly different from the detection rate from vagino-rectal specimens. Therefore, pregnant women do not need to be subjected to the discomfort of collection of a rectal specimen, as recommended by the 2002 CDC guidelines.

\section{References}

Centers for Disease Control and Prevention. Prevention of perinatal group B streptococcal disease: Revised Guidelines from the CDC. MMWR 2002;51(RR-11):1-22. 
Friday, August 6, 2004

\section{8:15 AM}

\section{Oral Presentations: Session III}

\section{UNIVALENT GBS VACCINE UTILIZING C5A PEPTIDASE ENCAPSULATED WITHIN BIODEGRADABLE POLYMERIC MICROSPHERES}

Stephen K. Hunter, MD., PhD. \& Mark Andracki, MS

Objective: Many group B streptococcal (GBS) vaccines utilize serotype-specific polysaccharide-protein conjugates but would need to be multivalent to protect against all GBS serotypes known to cause disease. Streptococcal C5a peptidase (C5A) is a surface protein that is conserved and expressed by all GBS serotypes. The encapsulation of antigen within biodegradable, polymeric microspheres provides many advantages not possible with free antigen. Our objective was to study the immune response, in mice, to C5a encapsulated within biodegradable polymeric microspheres as a potential, univalent GBS vaccine.

Study Design: C5a peptidase (gift from Wyeth) was encapsulated in polyglycolic acid (PLGA) microspheres. Mice were immunized with either PLGA microspheres containing C5a $(5 \mu \mathrm{g})$, free-unencapsulated C5a (5 $\mu \mathrm{g})$, or empty PLGA microspheres via an IM or nasal route. Booster doses at 14, 21, and 42 days were administered. Serum and vaginal wash $\operatorname{IgG}$ and $\operatorname{IgM}$ antibody response against C5a was determined by ELISA. Mice were also innoculated with GBS in the vaginal vault.and vaginal GBS cultures were obtained 48 hours after innoculation.

Results: PLGA/C5a microspheres elicited a significant systemic IgG antibody titer (1:40,000) three weeks after the initial immunization and increased up to a titer of $1: 100,000$ by 50 days with IM administration. IgG antibody titers increased from $1: 20,000$ to $1: 50,000$ with nasal vaccination, ( $P$ value $<0.004$ and 0.02 respectively). A lesser, but still significant, IgA response was seen in the vaginal mucosa with nasal administration (1:200 up to 1:1000). Culture results demonstrated no GBS colonization in mice vaccinated with the PLGA/C5a microspheres, while those receiving unencapsulated C5A or control PLGA microbeads had extensive GBS growth.

Conclusion: Results indicate that this novel PLGA/C5a vaccine produces a strongly significant antibody response at both the systemic and mucosal levels. This novel vaccine may prevent maternal mucosal GBS colonization while also providing passive transplacental immunization of the fetus and neonate. 
Friday, August 6, 2004

8:30 AM

Oral Presentations: Session III

\section{RELATIONSHIP BETWEEN VAGINAL UREAPLASMA UREALYTICUM, MYCOPLASMA HOMINIS AND GROUP B STREPTOCOCCI (GBS) AND IMMUNE ACTIVATION IN PREGNANT WOMEN}

AM Bongiovanni, K Duo, SS Witkin

Weill Medical College of Cornell University, New York, NY

Objectives: Delineation of the factors associated with vaginal colonization by individual microbes during pregnancy may lead to an improved understanding of the relation between composition of the vaginal flora and pregnancy outcome. The relationship between U. urealyticum, M. hominis and GBS vaginal colonization and vaginal concentrations of IL-1 system cytokines was evaluated.

Study Design: Vaginal specimens were obtained from 200 first trimester Black, Hispanic and White healthy pregnant women. Aliquots were tested for U. urealyticum, M. hominis and GBS by polymerase chain reaction (PCR) and for IL-1 $\beta$ and IL-1ra levels by ELISA. A length polymorphism in intron 2 of the IL-1ra gene (IL1RN) was determined by PCR. IL1RN allele 2 (IL1RN*2) has been associated with elevated IL-1ra production. Differences were analyzed by Mann-Whitney test and Fisher's exact test.

Results: $U$. urealyticum and GBS were detected in $33-45 \%$ and $12-17 \%$ of the women, respectively and did not differ by ethnicity. M. hominis was present in $22.4 \%$ of Hispanics, $19.8 \%$ of Blacks but in only $4.7 \%$ of Whites $(\mathrm{p}<.03)$. Both $M$. hominis and GBS colonization were associated with elevated vaginal IL- $\beta$ concentrations but unchanged IL-1ra concentrations. Conversely, $U$. urealyticum was associated with elevated IL-1ra concentrations and unchanged IL- $1 \beta$ levels. Carriage of IL1RN*2 was greatly reduced in Blacks as compared to the other ethnicities $(\mathrm{p}<.004)$ and its presence was associated with $U$. urealyticum colonization only in Whites $(\mathrm{p}=.0008)$.

Conclusions: $U$. urealyticum differs from $M$. hominis and GBS in the induction of an anti-inflammatory, rather than a pro-inflammatory, vaginal immune responses. Individual microorganisms may exert unique and opposing effects on vaginal immunity and may, depending on their relative and absolute concentrations, have different influences on pregnancy outcome.

Supported by NIH grant HD 41676 


\title{
Friday, August 6, 2004 \\ 9:00 AM \\ Oral Presentations: Session III
}

\section{THE INTERLEUKIN-1 $\beta$ + 3953 SINGLE NUCLEOTIDE POLYMORPHISM: CERVICAL PROTEIN PRODUCTION AND PRETERM DELIVERY RISK}

\author{
Rodney K. Edwards, MD, Ronald J. Ferguson, PhD, \& Patrick Duff, MD
}

Objectives: To determine the associations between preterm delivery (PTD), cervical fluid interleukin-1 $\beta$ (IL$1 \beta$ ) concentration, and the single nucleotide polymorphism at position +3953 in the IL-1 $\beta$ gene (allele 1 " $C$ "; allele 2 "T"). Allele 2 is associated with increased secretion of IL-1 $\beta$ in vitro.

Study Design: Cervical fluid samples were obtained with pre-weighed cellulose wicks from women 23-32 weeks gestation with signs and symptoms of preterm labor and intact membranes. Concentrations of IL- $1 \beta$ were determined with a commercially available ELISA. IL- $1 \beta$ genotyping was performed on DNA obtained from peripheral or cord blood using a PCR—RFLP technique.

Results: 137 women were enrolled, and complete delivery and genotype information was available for 128 . For women without, heterozygous for, and homozygous for allele 2, PTD rates were 23/87 (26\%), 11/36 (31\%), and $0 / 5(0 \%)(P=0.43)$. For the IL-1 $\beta$ concentrations, another 30 subjects were excluded because of visible staining of the cervical wick with blood. For women delivering preterm $(n=23)$ and at term $(n=75)$, respectively, mean \pm SD concentrations of IL- $\beta$ were $795.2 \pm 621.1$ and $499.9 \pm 576.5 \mathrm{pg} / \mathrm{ml}(P=0.04)$. For women with spontaneous PTD $(\mathrm{n}=19)$ and all others $(\mathrm{n}=79)$, respectively, IL-1 $\beta$ levels were $922.0 \pm 608.8$ and $484.4 \pm 566.3 \mathrm{pg} / \mathrm{ml}(P=0.004)$. For women without $(\mathrm{n}=64)$, heterozygous for $(\mathrm{n}=30)$, and homozygous for $(\mathrm{n}=4)$ allele $2, \mathrm{IL}-1 \beta$ concentrations were $485.8 \pm 479.6,671.5 \pm 676.5$, and $1137.6 \pm 1265.0 \mathrm{pg} / \mathrm{ml}(P=0.06$ for 3 group comparison and $P=0.06$ for women without compared to with allele 2 ). Neonatal IL- $1 \beta$ genotype was not associated with PTD or cervical IL-1 $\beta$ levels (data not shown).

Conclusions: Cervical fluid concentrations of IL-1 $\beta$ were elevated in symptomatic women destined to have a spontaneous PTD. Although the gene dosage of maternal IL-1 $\beta+3953$ allele 2 was associated with increased cervical fluid concentration of IL-1 $\beta$, it was not associated with risk of PTD. 
Friday, August 6, 2004

9:15 AM

Oral Presentations: Session III

\section{N-ACETYLCYSTEINE (NAC) SUPRESSES MATRIX METALLOPROTEINASES-9 MEMBRANE EXPRESSION IN RESPONSES TO MATERNAL LIPOPOLYSACCARIDE (LPS)}

Ron Beloosesky MD, Dave A Gayle PhD, Fataneh Amidi MD, Jooby Babu MD, Mina Desai PhD, \& Michael G Ross MD, MPH.

Obstetrics and Gynecology, Harbor-UCLA Medical Center, Torrance, CA, USA

Objective: Fetal infection, inflammation and oxidant stress have been implicated in the genesis of preterm prelabour rupture of the fetal membranes (PPROM). Matrix metalloproteinases-9 (MMP-9) which is implicated in the mechanism of membrane rupture, is increased in fetuses with PPROM. Changing the redox balance by enhancing antioxidant activity may prevent PPROM. We sought to determine whether NAC, a known antioxidant, can blunt the membrane expression of MMP-9 following LPS injection to pregnant rats.

Study Design: Pregnant Sprague Dawley rats at 18 days gestation were studied. Maternal rats received intraperitoneal injections of saline (Sal) or NAC $(800 \mathrm{mg} / \mathrm{kg}$ ) at time 0 , followed by intraperitoneal LPS $(100 \mathrm{mg} / \mathrm{kg})$ at time $30 \mathrm{~min}$, and intraperitoneal saline or NAC $(800 \mathrm{mg} / \mathrm{kg}$ ) at time $150 \mathrm{~min}$ (Sal-LPS-Sal, NAC-LPS-NAC). An additional group received intraperitoneal saline at time 0,30 , and at $150 \mathrm{~min}$. At $6 \mathrm{~h}$ after the first injection, rats were sacrificed, MMP-9 mRNA expression in the membrane were determined by real time PCR.

Results: In response to maternal LPS (Sal-LPS-Sal), there was a trend of increase in the membrane expression of MMP-9 compared to the control group, which did not reach statistical significant. Treatment with NAC prior to, and after LPS (NAC-LPS-NAC) significantly $(\mathrm{p}<0.05)$ reduced the expression of the membranes MMP-9 from the control group and the LPS group $(2 \pm 0.27,5.73 \pm 1.73,7.47 \pm 2.62$ for the NAC-LPSNAC, SAL-SAL-SAL, SAL-LPS-SAL group respectively).

Conclusion: Maternal NAC dramatically decreases the membranes MMP-9 expression in responses to maternal LPS or saline injection. These results suggest that NAC may protect the fetus from PPROM. 


\section{Friday, August 6, 2004 \\ 9:45 AM \\ Oral Presentations: Session IV}

\section{IMPACT OF CHORIOAMNIONITIS ON PLACENTAL EXPRESSION OF PROSTAGLANDIN METABOLIZING ENZYMES}

Emmet Hirsch, MD, Marci Goldstein, BS, Yana Filipovich, BS and Hao Wang, PhD

Department of Obstetrics and Gynecology, Evanston Northwestern Healthcare and Feinberg School of Medicine, Northwestern University, Evanston, IL

Objectives: The purpose of this study was to characterize the impact of clinical chorioamnionitis on expression of prostaglandin (PG)-metabolizing enzymes in human placentas. Enzymes studied included cyclooxygenase 1 (COX1, the constitutive form of PG synthase), COX2 (the inducible form) and prostaglandin dehydrogenase (PGDH, a degrading enzyme).

Study Design: Women between 20 and 37 weeks' gestation with spontaneous labor or premature rupture of membranes $(\mathrm{ROM})$ and term controls ( $\geqslant 37$ weeks, matched by race/ethnicity, payor and parity) were enrolled in a prospective case-control study. After delivery, a $0.5 \mathrm{~cm}$ cube of placenta was obtained from the maternal surface and preserved in RNALater (Ambion). Total RNA was extracted and poor quality samples were excluded. TaqMan ${ }^{\mathbb{R}}$-based real-time quantitative PCR was used to determine the relative amounts of the RNAs of interest normalized to $18 \mathrm{~S}$ RNA. In our institution, uninfected patients in preterm labor with intact membranes receive tocolysis. Patients with ROM and no infection are managed expectantly (with an initial 7 days of antibiotics) until 34 weeks, when labor is induced. Maternal steroids are administered up to 34 weeks (32 weeks with ROM).

Results: 41 preterm (average GA 31.6 weeks) and 39 term (average GA 39.4 weeks) placentas were studied. Twelve patients (15\%) had chorioamnionitis, of whom 8 delivered prior to 37 weeks. Thirteen (16\%) were delivered by cesarean section, of whom 12 had first labored. Placental expression of COX1 was $43 \%$ higher in patients with chorioamnionitis than uninfected patients $(p=0.006)$. No such differences existed for COX2 or PGDH. Enzyme expression for all tested enzymes did not vary whether patients presented with ROM or labor with intact membranes.

Conclusions: Placental expression of the constitutive form of prostaglandin synthase (COX1), but not the inducible form (COX2), is increased with chorioamnionitis. This information is important for understanding the mechanisms by which maternal and fetal tissues impact upon labor onset. 


\title{
Friday, August 6, 2004
}

10:00 AM

\section{Oral Presentations: Session IV}

\section{CERVICAL ANTI-INFLAMMATORY CYTOKINE CONCENTRATIONS ARE INCREASED AMONG PREGNANT SMOKERS}

\author{
H.N. Simhan, MD, S.N. Caritis, MD, S.L. Hillier, PhD, \& M.A. Krohn, PhD \\ University of Pittsburgh, Department of Obstetrics, Gynecology and Reproductive Sciences, Pittsburgh, PA
}

Objectives: Cigarette smoking is known to alter many aspects of immunity. The production and activity of anti-inflammatory cytokines are thought to be a critical element of the lower genital tract innate immune defense with respect to STDs and infection-related spontaneous preterm birth. We sought to ascertain the impact of cigarette smoking in pregnant women on the production of the three most important anti-inflammatory cytokines (IL-4, IL-10, and IL-13) in the cervix.

Study Design: In this ongoing cohort study, forty-six gravid women from 4 to 16 weeks' gestation (median 8.4 weeks') without BV or STDs were queried regarding clinical and demographic history and underwent pelvic examination for collection of vaginal swabs for Gram stain and cervical swabs for STDs and cytokines. Concentrations of cytokines were determined in duplicate using Luminex( multiplex assay. Smoking status was determined by self-report. Statistical analyses were performed using Stata 8.0.

Results: Among the 21 non-smokers and 25 smokers, there is a statistically significant positive linear relationship between number of cigarettes smoked per day during pregnancy and cervical concentration of IL-4, IL-10, and IL-13 ( $<0.002$ for all three). Women who reported smoking more than $\frac{1}{2}$ pack per day during pregnancy were 5.75 times more likely to have cervical IL-4 concentration above the highest quartile $(p=0.03)$ than women who smoked less than this amount. These heavier smokers were also 7.2 times more likely to have cervical IL-10 concentration above the highest quartile $(p=0.01)$ than lighter smokers. The frequency of IL-13 above the highest quartile was 4 times greater among heavier smokers than lighter smokers, although this did not reach statistical significance. $(p=0.06)$.

Conclusions: Cigarette smoking in pregnancy is associated with an alteration of cervical innate immunity, as represented by the three most important anti-inflammatory cytokines. This may have important impact upon the host response to immune challenges, such as STDs or infection-related preterm birth. 


\title{
Friday, August 6, 2004
}

10:15 AM

\section{Oral Presentations: Session IV}

\section{PRO-INFLAMMATORY CYTOKINES AND OTHER CELL SIGNALING ANALYTES ASSOCIATED WITH BACTERIAL VAGINOSIS AMONG PREGNANT WOMEN}

\author{
M A Krohn PhD, H N Simhan MD, MS., M Yudin MD, MS, S L Hillier PhD, S N Caritis MD \\ University of Pittsburgh, Department of Obstetrics, Gynecology, and Reproductive Sciences, Pittsburgh PA
}

Objectives: Bacterial vaginosis (BV) precedes and elevates the risk of acquiring STIs and HIV-AIDS. Investigators know little about how BV changes the cervical and vaginal cells to increase their vulnerability to STIs. We evaluated pro-inflammatory, cell signaling, and growth factor analytes which could decrease the protection of the normal genital tract epithelium.

Study Design: A case-control study of women with $(n=46)$ and without $(n=49)$ BV was conducted 20012003. Women from 5 to 20 weeks gestation were enrolled if their Gram-stained vaginal smear was classified as $\mathrm{NL}$ or BV by the Nugent score. Cervical specimens were assayed in duplicate using Lumine $\times 100$ LabMap $^{\mathrm{TM}}$ and Beadlyte ${ }^{\circledR}$ antibody kits. Analytes were deemed associated with BV if they were statistically significant by $\chi^{2}$ and Kruskal-Wallis tests $(\mathrm{P}<0.001)$, and logistic regression models fit as natural log transformed continuous variables adjusted for race with the $95 \%$ CI not including 1 . Demographic and behavioral characteristics were ascertained by a personal interview.

Results: Women with BV were more frequently African-American, lacking vaginal $\mathrm{H}_{2} \mathrm{O}_{2}$ producing Lactobacillus, currently smoking, and more likely to have anaerobic pigmented Gram-negative rods. Interleukin $1-\alpha$ was elevated 2.3 multiples of the median (MOM) from $837 \mathrm{pg} / \mathrm{ml}$ in women without BV, IL- $1 \beta$ was elevated 9.1 MOM from 109 median pg/ml, and Vascular Endothelial Growth Factor (VEGF) was elevated 10.3 MOM from 521 median $\mathrm{pg} / \mathrm{ml}$ among women with a normal vaginal smear. Interleukin-7 was decreased $50 \%$ in women with BV compared with those without BV.

Conclusions: As expected, cervical pro-inflammatory cytokines, IL- $1 \alpha$ and $\beta$, were associated with BV. In addition, VEGF, which stimulates neovascularization, was markedly elevated in women with BV. IL-7, required for the homeostasis of memory $\mathrm{T}$ cells, was reduced in women with BV. Neovascularization and naïve T cells may be an important part of the influence BV has in raising susceptibility to other STIs. 
Friday, August 6, 2004

10:30 AM

Oral Presentations: Session IV

\section{ASYMPTOMATIC TRICHOMONIASIS DURING PREGNANCY IS ASSOCIATED WITH VAGINAL NEUTROPHIL ACTIVATION}

B.L. Anderson, MD, H.N. Simhan, MD, MSCR, H.C. Wiesenfeld, MD, CM, R.P. Heine, MD, M.A. Krohn, PhD, D.V. Landers, MD, S.N. Caritis, MD, B.M. de Tejada, MD, S.L. Hillier, PhD

Objectives: The presence of vaginal neutrophils is associated with upper genital tract infection, both in nonpregnant (e.g. PID) and pregnant (e.g. early preterm birth) women. Vaginal neutrophil defensins and IL-8, products of neutrophil activation, are thought to be integral mediators of host defense. Observational studies have shown that trichomoniasis is associated with poor pregnancy outcomes. The purpose of the study was to determine if asymptomatic $T$. vaginalis infection in early pregnancy is associated with neutrophil activation.

Study Design: This study was a nested cohort of eighty-five pregnant women at between 8 and 20 weeks' gestation. Twenty-eight women with and fifty-seven women without trichomoniasis were enrolled. None of these women had bacterial vaginosis, gonorrhea, or chlamydia. Neutrophil defensin (human neutrophil peptides 1-3) and IL-8 concentrations were measured by ELISA. Kruskal-Wallis test was used to compare concentrations between groups. Neutrophil number was determined by Gram stain vaginal smear.

Results: The proportion of women with any neutrophils was similar between the groups. $60 \%(17 / 28)$ of the women with trichomoniasis versus $47 \%(124 / 264)$ of the women without trichomoniasis had any neutrophils, $\mathrm{p}=0.24$. The median defensin concentration in women infected with $T$. vaginalis was $40,124 \mu \mathrm{g} / \mathrm{mL}$ versus $14,439 \mu \mathrm{g} / \mathrm{mL}(\mathrm{p}=0.002)$ for uninfected women. The median IL-8 concentration was also greater in women infected with $T$. vaginalis than in uninfected women $(9599 \mathrm{pg} / \mathrm{mL}$ vs. $2889 \mathrm{pg} / \mathrm{mL}, \mathrm{p}=0.0001)$.

Conclusion: Neutrophil defensin and IL-8 concentrations are increased in the presence of trichomoniasis in early pregnancy, even in the absence of symptoms or an increase in the numbers of neutrophils in vaginal fluid. This neutrophil activation suggests that asymptomatic trichomoniasis triggers an inflammatory response and should not be regarded as a benign condition. 


\section{Saturday, August 7, 2004 \\ 9:00 AM \\ Oral Presentations: Session V}

\section{A POOLED ANALYSIS OF RISK OF NEONATAL HSV INFECTION BY MATERNAL SEROSTATUS AT DELIVERY}

Brown E.L., BA, Gardella C., MD, MPH, Malm G., MD, PhD, Forsgren M., MD, PhD, Krantz E., MS, Zeh J., PhD, Corey L., MD, Wald A., MD, MPH

Objectives: To determine whether the risk of neonatal herpes simplex virus (HSV) varies according to maternal HSV serostatus at delivery.

Study Design: We conducted a pooled analysis of data from Seattle, Washington and Stockholm, Sweden. In Seattle, we obtained maternal serology data from a prospective cohort of 31,645 pregnant women followed between 1982 and 1999, during which 15 cases of neonatal HSV occurred. In Stockholm, we obtained data on 34 neonatal HSV cases which occurred between 1972 and 2001, as well as serologic data from 3700 pregnant women from the same population who did not transmit HSV to the neonate.

Results: Overall, 16 infants (6 in Seattle, 10 in Stockholm) had HSV-1 and 33 (9 in Seattle, 24 in Stockholm) had HSV-2 infection. The calculated rates of neonatal HSV were 54 (95\% CI: 19.8-118) and 9 (4.6-15.6) per 100,000 live births among HSV seronegative women in Seattle and Stockholm, respectively. Rates among HSV1 seropositive/HSV-2 seronegative women were 26 (9.3-56) (Seattle) and 4 (2.0-7.0) (Stockholm) and rates among all HSV-2 seropositive women were 22 (4.4-64) (Seattle) and 6 (3.0-10.9) (Stockholm). The risk of any neonatal HSV infection in seronegative women compared with HSV-2 seropositive women was somewhat elevated (odds ratio (OR):1.7, 95\% CI: 0.8-3.5), while that for HSV-1 seropositive women compared with HSV-2 seropositive women was not (OR: $0.8,95 \%$ CI: 0.4-1.7). The risk of neonatal HSV-1 infection in seronegative women compared with HSV-1 seropositive women was significantly elevated (OR: 4.4, 95\% CI: 1.5-12.6). The risk of neonatal HSV-2 infection was similar in seronegative women compared with HSV-1 seropositive women (OR: 1.1, 95\% CI: 0.4-2.9).

Conclusion: Rates of neonatal HSV infection are higher in Seattle than in Stockholm. Antibodies to HSV-1 do not appear to reduce the risk of transmission of HSV-2 to the neonate. In both cities, the highest rate of neonatal $\mathrm{HSV}$ is in seronegative women. 


\section{Saturday, August 7, 2004 \\ 9:15 AM \\ Oral Presentations: Session V}

\section{CYTOMEGALOVIRUS IN BREAST MILK: DOES IT MAKE VERY PREMATURE BABIES ILL?}

CJ Morley, R Lau, S Garland, N Curtis, S Tabrizi, R Alexander, \& A Tigg

Neonatal Services, Royal Women's Hospital, Melbourne, and Dept Microbiology, Royal Children's Hospital, Melbourne and Dept Infectious Diseases, Royal Children's Hospital, Melbourne, Australia

Objectives: To determine, in very premature babies born in the Royal Women's Hospital, the incidence and severity of illnesses caused by CMV shed in their mothers' fresh unfrozen expressed breast milk (EBM).

Study Design: Mothers of babies born at $<32$ weeks and $<1500 \mathrm{~g}$ were invited to join the study. Only CMV antibody + ve mothers were enrolled. EBM and babies' urine and saliva were collected weekly, until discharge, for culture. All new neonatal symptoms, signs and treatments were documented.

Results: 247 mothers were approached, 202 consented. Mothers of 95 babies were CMV antibody + ve (47\%). 88 babies and their 75 mothers were studied. The mean (SD) mothers' age was 29 (6) y, parity 2.2 (1.3), and babies' birth weight $937(212) \mathrm{g}$, 33\% were delivered vaginally, $47 \%$ were male and 30\% twins.

CMV was cultured from EBM deposit and supernatant starting at week 1 in $66 \%$ of the EBM that was culture + ve at any time. $33 \%$ of the babies grew CMV in urine or saliva starting about week $7.97 \%$ of the CMV culture + ve infants had CMV culture + ve EBM. $66 \%$ of the CMV culture -ve infants had CMV + ve EBM.

\begin{tabular}{lccc}
\hline Neonatal illnesses & CMV culture +ve & CMV culture -ve & p \\
\hline Platelets $<100,000$ & $24 \%$ & $24 \%$ & NS \\
$\mathrm{O}_{2}$ at 36 weeks & $28 \%$ & $17 \%$ & $\mathrm{NS}$ \\
Hepatomegaly & $3 \%$ & $2 \%$ & $\mathrm{NS}$ \\
Apnoea $>3 /$ hour or bagging & $52 \%$ & $49 \%$ & $\mathrm{NS}$ \\
CPAP episodes & $59 \%$ & $41 \%$ & $\mathrm{NS}$ \\
Abdominal distension episodes & $66 \%$ & $64 \%$ & $\mathrm{NS}$ \\
\hline
\end{tabular}

Conclusion: About half the mothers of very premature babies are CMV antibody + ve. Two-thirds shed CMV in their EBM from the first week. 33\% of the babies of CMV antibody + ve mothers grew CMV from the urine or saliva. They had no more signs or symptoms of illness than the babies who remained CMV culture -ve. CMV acquired from mother's EBM by very premature babies did not have significantly more illnesses than babies from CMV antibody + ve mothers who were not infected. 


\section{Saturday, August 7, 2004 \\ 9:45 AM \\ Oral Presentations: Session VI}

\section{MEASUREMENT OF INTERLEUKIN 8 IN COMBINATION WITH C-REACTIVE PROTEIN REDUCED UNNECESSARY ANTIBIOTIC THERAPY IN NEWBORN INFANTS: A MULTICENTER RANDOMIZED CONTROLLED TRIAL}

Axel R. Franz; Karl Bauer; Andreas Schalk; Suzanne M. Garland ${ }^{1}$, et al. for the International IL-8 Study Group ${ }^{1}$ Department of Microbiology and Infectious Disease, The Royal Women's Hospital, Women's and Children's Health, Carlton, Victoria 3053, Australia

Objective: Neonatal bacterial infections carry a high mortality if diagnosed late. Early diagnosis is difficult because initial clinical signs are nonspecific. Consequently, physicians frequently prescribe antibiotic treatment to newborn infants for fear of missing a life-threatening infection. This study test the hypotheses that a diagnostic algorithm including measurements of interleukin 8 (IL-8) and C-reactive protein (CRP) (1) reduces antibiotic therapy and (2) does not result in more initially missed infections compared with standard management (no IL-8).

Study Design: Infants $<72$ hours of age, with clinical signs or obstetric risk factors suggesting neonatal bacterial infection but stable enough to wait for results of diagnostic tests, were enrolled into the study. A total of 1291 infants were randomly assigned to receive antibiotic therapy according to the guidelines of each center (standard group) or to receive antibiotic therapy if IL-8 were $>70 \mathrm{pg} / \mathrm{mL}$ and/or CRP was $>10 \mathrm{mg} / \mathrm{L}$ (IL-8 group). The primary outcome variables were (1) number of infants treated with antibiotics; (2) number of infants with infections missed at the initial evaluation.

Results: In the IL-8 group, fewer infants received antibiotic therapy than in the standard group (36.1\% (237/ $656)$ versus $49.6 \%$ (315/635); $\mathrm{p}<0.0001)$. For the former, $24(14.5 \%)$ of 165 infants with infection were detected at the initial evaluation, compared with 28 (17.3\%) of 162 in the standard group (n.s.).

Conclusions: The number of newborn infants receiving postnatal antibiotic therapy can be reduced with a diagnostic algorithm, including IL-8 and CRP. (This diagnostic strategy appeared to be safe.) 


\section{Saturday, August 7, 2004 10:00 AM Oral Presentations: Session VI}

\section{PREVALENCE \& RISK FACTORS FOR HIV IN SOUTHERN AFRICAN WOMEN}

Amy Meehan M.P.H.*1, Chidanyika A. ${ }^{2}$, Naidoo S. ${ }^{3}$, Didier L. ${ }^{1}$, Ramjee G. ${ }^{3}$, Chipato T. ${ }^{2}$, Dinat N. ${ }^{4}$, Ellertson C. ${ }^{5}$, MIRA team \& Padian N. ${ }^{1}$

${ }^{1}$ University of California, San Francisco, California, ${ }^{2}$ UZ-UCSF Collaborative Research Programme in Women's Health, Harare, Zimbabwe, ${ }^{3} M R C$, Durban, RSA, ${ }^{4}$ PHRU, Fohannesburg, RSA, and ${ }^{5}$ Ibis Reproductive Health, Massachusetts

Background: Over half of all HIV infections in Southern Africa are among women. Women are more vulnerable for biological, economic, and social reasons.

Objectives/Study Design: The Methods for Reproductive Health in Africa (MIRA) study is an ongoing randomized controlled trial of 4500 women in Zimbabwe (Harare) and South Africa (Durban \& Soweto) to examine the effectiveness of the diaphragm and Replens ${ }^{\circledR}$ gel in preventing HIV acquisition. Women were interviewed and tested for STIs as part of screening procedures. 734 completed testing to date. We used a multivariate logistic regression model to identify predictors of HIV.

Results: The mean age of the women screened was 29 (range $16-70)$; most were married (88\%), lived with their husband/partner $(88 \%)$, and had $\geqslant 11$ years of education $(53 \%)$. The majority reported having one lifetime partner $(66 \%)$, being $\geqslant 16$ at first sex $(79 \%)$, and having used a male condom (79\%). Although these women reported low-risk behaviours, $40 \%$ were HIV positive. HIV prevalence was $13 \%$ for women ages $18-20$; $51 \%$ for ages $21-30 ; 26 \%$ for ages $31-40$; and $10 \%$ for ages over 40 . There was a high prevalence $(44 \%)$ of HSV-2 infection (ELISA), but a low prevalence of curable STIs. $2 \%$ tested positive for chlamydia and gonorrhoea; $4 \%$ for trichomoniasis (urine PCR); and $<1 \%$ for syphilis. After controlling for age, education, marital status, living with husband/partner, and age at first sex, only having $>1$ lifetime partner was significantly associated with being $\mathrm{HIV}$ positive $(\mathrm{OR}=1.2,95 \% \mathrm{CI}: 1.1-1.3)$.

Conclusions: The high prevalence of HIV infection in women in this trial reinforces the need for femalecontrolled methods of prevention. 


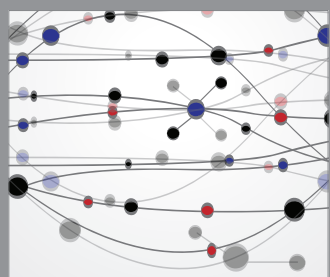

The Scientific World Journal
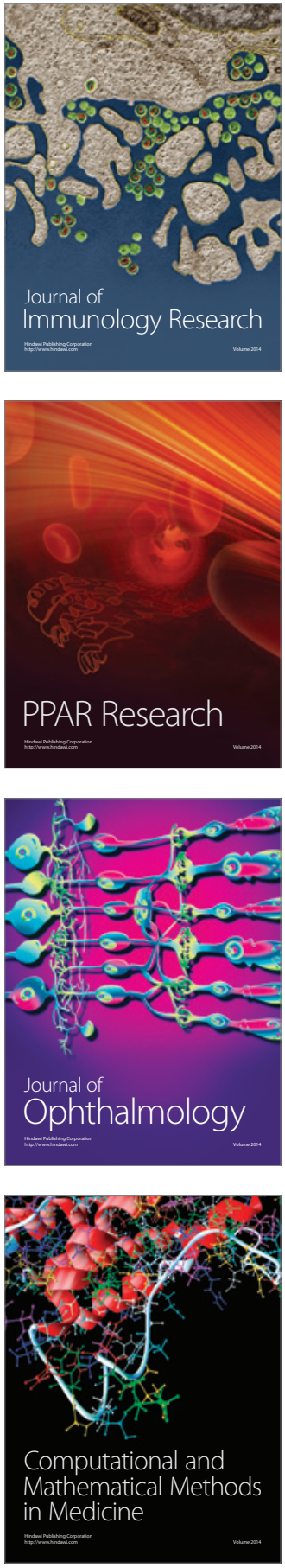

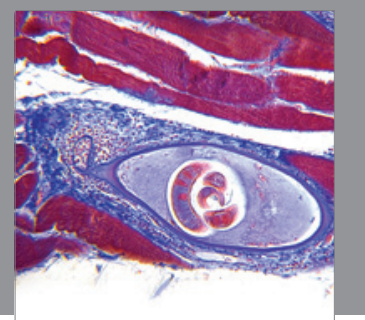

Gastroenterology

Research and Practice
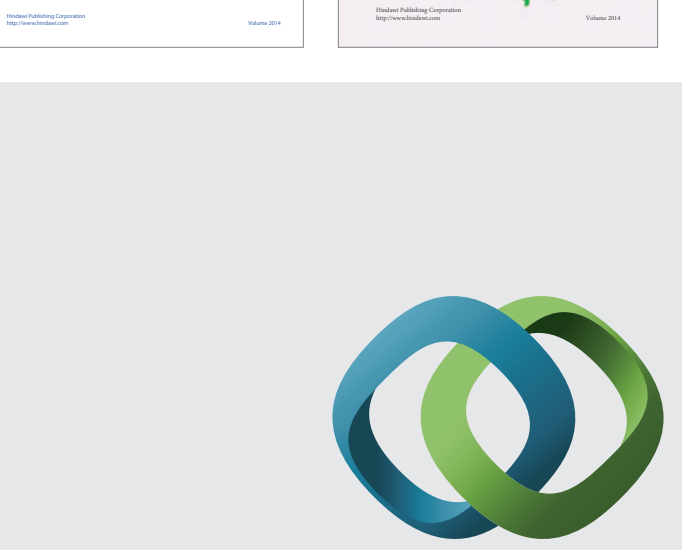

\section{Hindawi}

Submit your manuscripts at

http://www.hindawi.com
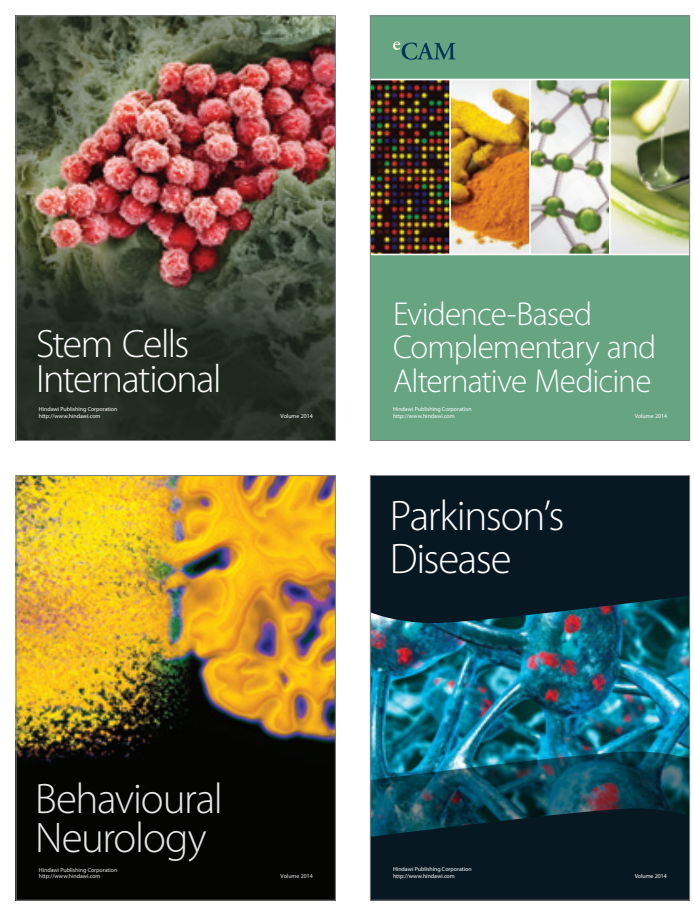

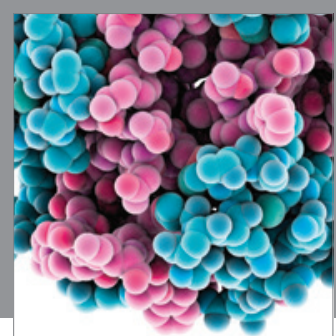

Journal of
Diabetes Research

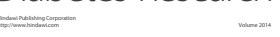

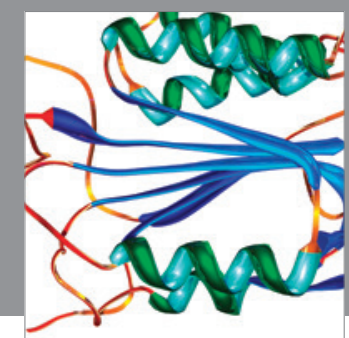

Disease Markers
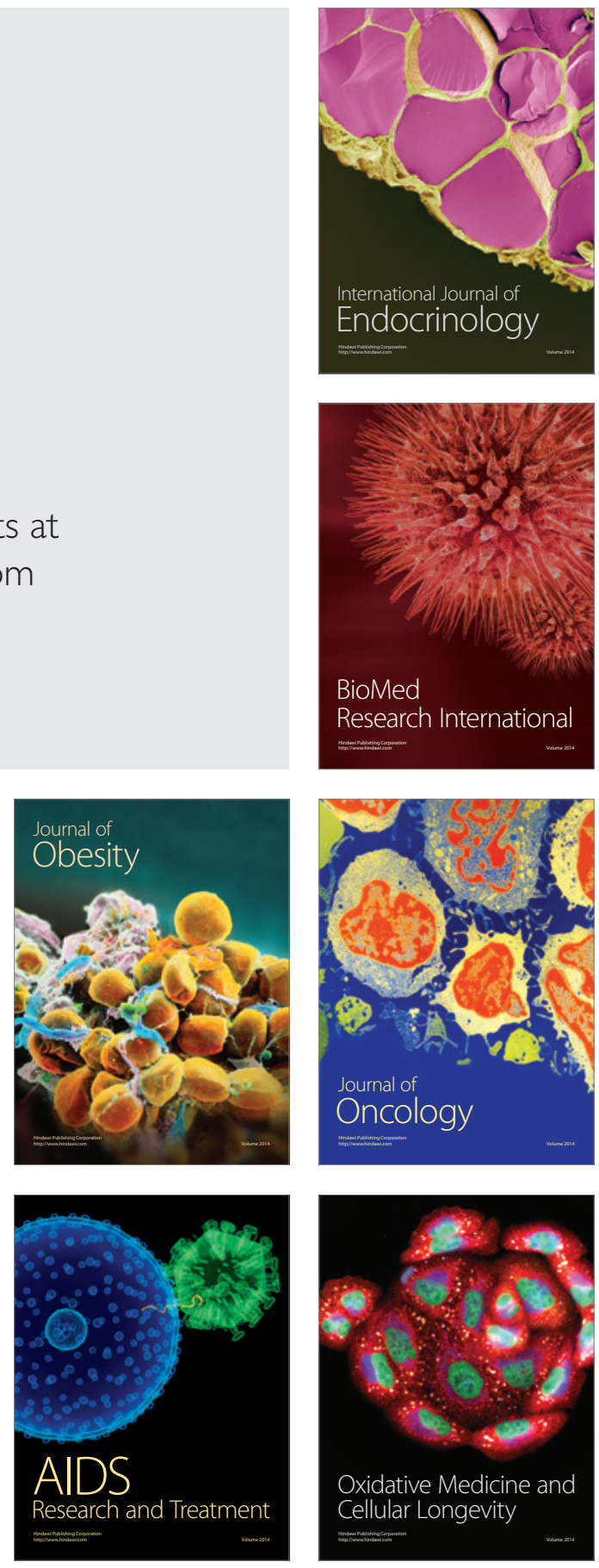